Portland State University

PDXScholar

$5-6-1994$

\title{
The Preferred Learning Styles of Greek EFL Students and Greek EFL Teachers
}

Debra Jane Gregory

Portland State University

Follow this and additional works at: https://pdxscholar.library.pdx.edu/open_access_etds

Part of the Speech and Rhetorical Studies Commons

Let us know how access to this document benefits you.

\section{Recommended Citation}

Gregory, Debra Jane, "The Preferred Learning Styles of Greek EFL Students and Greek EFL Teachers" (1994). Dissertations and Theses. Paper 4836.

https://doi.org/10.15760/etd.6712

This Thesis is brought to you for free and open access. It has been accepted for inclusion in Dissertations and Theses by an authorized administrator of PDXScholar. Please contact us if we can make this document more accessible: pdxscholar@pdx.edu. 


\section{THESIS APPROVAL}

The abstract and thesis of Debra Jane Gregory for the Master of Science in Speech Communication were presented May 6, 1994 and accepted by the thesis committee and the department.

COMMITTEE APPROVALS:

Devorah A. Liebermah, Chair

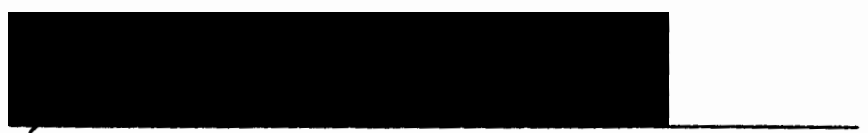

Susan B. Poulsen

DEPARTMENT APPROVAL:

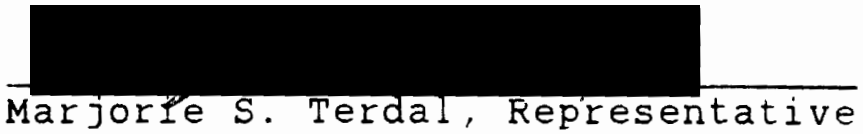
of the office of Graduate studies

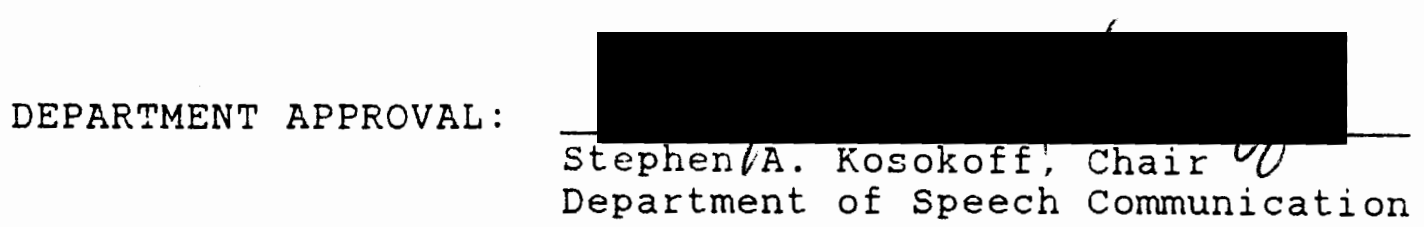

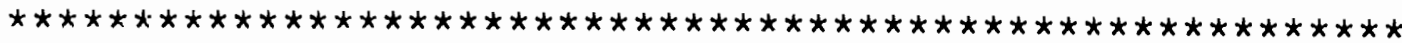

ACCEPTED FOR PORTLAND STATE UNIVERSITY BY THE LIBRARY by on

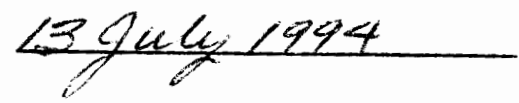




\section{ABSTRACT}

An abstract of the thesis of Debra Jane Gregory for the Master of Science in Speech Communication: presented May 5, 1994 .

Title: The Preferred Learning styles of Greek EFL Students and Greek EFL Teachers.

The purpose of this study was to identify the preferred learning styles of Greek EFL students and teachers in Greece. The learning styles examined were visual, auditory, kinesthetic, tactile, group and individual. The study was conducted at a private English language school in Piraeus, Greece. Ninety-two Greek EFL students ( 33 male and 59 female) ranging in age from 13 to 22, and 11 Greek EFL teachers ( 3 male and 8 female) ranging in age from 22 to 52 constitute the sample. The study used the self-reporting learning style questionnaire that Reid (1987) developed to measure the preferred learning style preferences of ESL students in the U.S., and is a partial replication of Reid's study. The instrument was used to determine the major, minor and negligible preferred learning styles of Greek EFL students and teachers. 
Data from the learning style questionnaires were analyzed using paired t-tests, unpaired t-tests, singlefactor and two-factor ANovAs. Statistical analysis indicated kinesthetic learning as a major learning style for students, and visual, kinesthetic and tactile learning as major learning style preferences for teachers. No negligible learning styles were reported for either group. students tended to prefer teacher-centered learning styles (visual, auditory and individual learning) slightly more than student-centered learning styles (kinesthetic, tactile and group learning). Furthermore, teachers tended to prefer student-centered learning styles slightly more than teacher-centered learning styles. Data from both groups (teachers and students) suggested interaction effects for age and gender.

The results of this study raise questions concerning the reliability of Reid's instrument. Neither subject groups in this study, nor subjects in Hoffner's (1991) or Pia's (1989) studies, identify negligible learning styles on the part of the subjects. This raises questions related to the reliability of Feid's instrument. It suggests that further study needs to be conducted in measuring learning style preferences in culture specific studies. 


\title{
THE PREFERRED LEARNING STYLES OF GREEK EFL STUDENTS AND GREEK EFL TEACHERS
}

\author{
by
}

DEBRA JANE GREGORY

A thesis submitted in partial fulfillment of the requirements for the degree of

\author{
MASTER OF SCIENCE \\ in \\ SPEECH COMMUNICATION
}

\author{
Portland State University \\ 1994
}


TABLE OF CONTENTS

EAGE

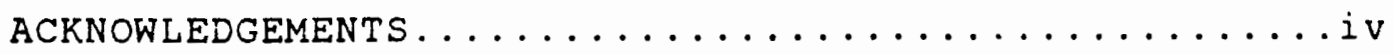

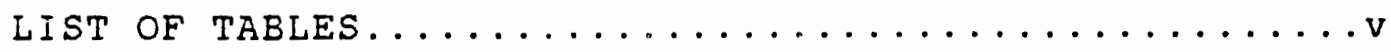

\section{CHAPTER}

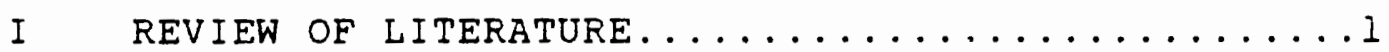

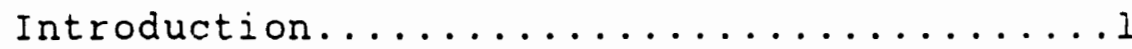

Purpose of the study

Research Questions

Hypotheses

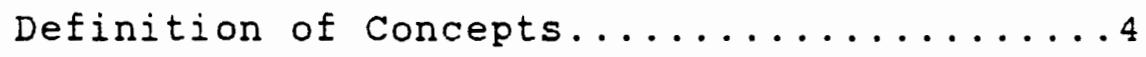

Significance of the study............

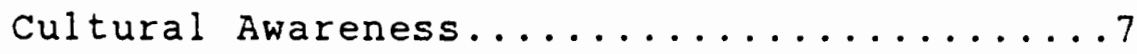

Approaches to Language Learning..........10

Teacher-centered

student-centered

Learner-centered

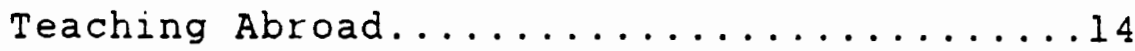

The current Situation in Greece.........16

Greek Ministry of Education

Attempts at Educational Reform

Failure To Keep Up With

International Trends

Cultural Influence on student

Motivation 


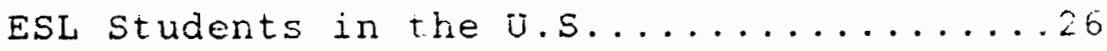

Factors Interfering with Language Learning

Curricul um Deveiopment

Self Report questionnaire

summary..........................

I I METHOD .........................

Sampling Frame..................44

sample......................... 48

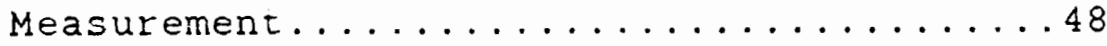

Instrument

Validity and Reliability

Demographic Data

Research Procedures...............51

Translation Procedure

Pilot study

Data collection Procedure

Data Analysis...................... 44

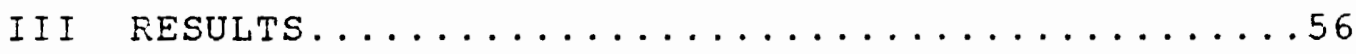

Greek EFL Teachers and Greek EFL Students 56

Combined Scores of Teachers and

students

Mean Scores For Teachers and

students

Subgroups of Greek EFL students...........

Gender

Age

IV DISCUSSION AND CONCLUSION..............68

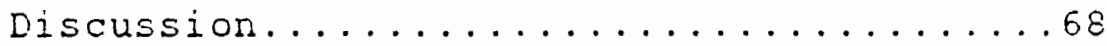

Hypotheses

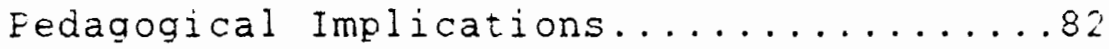




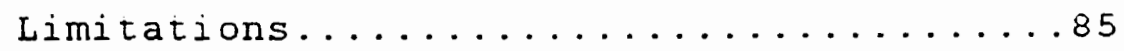

Considerations for Future Fesearch......89

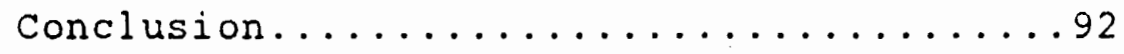

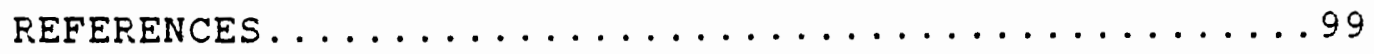

APPENDICES

A COVER LETTERS....................

B INFORMED CONSENT.................

C PERCEPTUAL LEARNING STYLE PREFERENCE QUESTIONNAIRE..........113

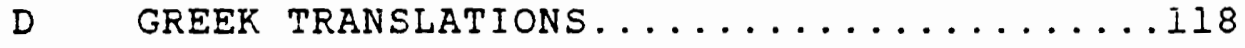

E BACKTRANSLATIONS INTO ENGLISH.......... 128

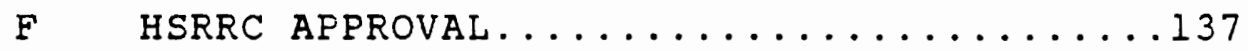

G LETTER FROM JOY REID.................

H FAX FROM PAPAELIOU SCHOOL..................

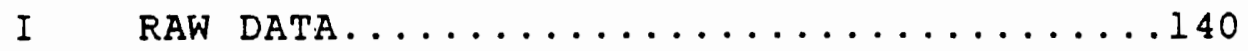




\section{ACKNOWLEDGEMENTS}

I would like to take this opportunity to express my gratitude to all who helped me with the completion of this Master's thesis. This was an exercise in self awareness, as much as it was an exercise in social science research.

First I would like to thank my committee members for their advice and encouragement throughout the completion of this thesis. I am grateful to Dr. Devorah Lieberman, Chair, who guided me through her practical approach to academia, by allowing me to view the thesis not as an unavoidable burden, but as a workable goal. I thank Dr. Susan Foulsen for her insight and careful consideration of all material presented to her. I also would like to thank Dr. Marjorie Terdal, whose TESOL expertise has influenced me both professionally and academically.

Finally, I would like to thank all the friends and family who have made the completion of this thesis possible. I thank Nick for his help in arranging the research site. I also thank Aristotelis and Natasha for the translation and delivery of the questionnaires. Most of all, I thank Yiannis and Mersene for their love and support. 


\section{LIST OF TABLES}

TABLE

PAGE

I

Combined scores of Teachers and Students

58

I I

Mean Scores for EFL Teachers and EFL Students

I I I

Faired t-Test for Preference Means of student-centered and Teacher

-centered Learning styles

IV

Unpaired $t$-Test for student Mean Scores and Teacher Mean Scores

V

Mean Scores for Male and Female students

V I

Two-Factor Anova for Male and Female Students

Mean Preference Scores for Age Groups 
CHAPTER I

REVIEW OF LITERATURE

INTRODUCTION

For the past two decades, TESOL methodology has promoted the student-centered approach in which the student, rather than the teacher, is the center of attertion. Activities that focus on the students (Enright \& McCloskey, 1985; Bowen, Madsen \& Hilferty, 1985; and Long \& Forter, 1983) are believed to lower student anxiety in the classroom and hence lead to greater language learning (Dulay \& Burt, 1985; Krashen, 1982).

During the past five years, researchers in the field have explored how students of English as a second or foreign language feel about student-centered instruction (Katz, 1989; Little \& Sanders, 1990; Feid, 1987). Methods and materiais designed for ESL/EFL are often student-centered. These activities may be ineffective with students of particular cultures when the preferred learning styles of those cultures differ from the preferred learning styles of native speakers of English. The contemporary learner-centered approach, as differentiated from what has been commonly known as the 
student-centered or "communicative" approach, considers how students' learning styles affect their language acquisition. It is a response to the resistance that some students feel toward the student-centered approach. As part of the learner-centered approach, teachers and learners collaborate on what and how the students will be taught (Nunan, 1988).

\section{Purpose of The study}

The main purpose of this study was to identify the preferred learning styles of Greek students and Greek teachers of English as a foreign language. This was a culture specific study conducted in Greece; therefore, only native Greeks participated in the survey. According to shuter (1990), culture specific research "provides a conceptual basis for making intercultural comparisons between dissimilar cultures" (p. 243). The researcher, who is a member of U.S. culture, gathered comprehensive data on the learning style preferences of native Greeks who either study or teach English in Greece. It is hoped that this information will familiarize non-Greek EFL teachers with English language study in Greece, as well as provide the foundation for a possible comparison between EFL classes in Greece and ESL classes in the U.S. 
Research questions

The researcher formulated the following questions based on the literature review and her own experience teaching English in Greece.

1. What learning styles do Greek EFL students report they prefer?

2. What learning styles do Greek EFL teachers report they prefer?

3. What learning styles do Greek EFL teachers report their students prefer?

4. What are the similarities and differences between the learring styles that Greek EFL students and Greek EFL teachers report they prefer?

5. What are the similarities and differences between the learning styles that male and female Greek EFL students report they prefer?

6. What are the similarities and differences between the learning styles that Greek EFL students 13-17 and Greek EFL students 18-22 report they prefer?

\section{Hypotheses}

The following hypotheses were constructed based on the literature review and the researcher's own experience teaching English in Greece:

Hi: Greel EFL students will report that they prefer teacher-centered learning styles.

H2: Greek EFL teachers will report that they prefer student-centered learning styles.

H3: Greek EFL teachers will report that their students prefer student-centered learning 
styles.

H4: There will be a significant difference between the preferred learning styles of Greek.

EFL students and Greek EFL teachers.

H5: There will be a significant difference between the preferred learning styles of male and female Greek EFL students.

H6: There will be a significant difference between the preferred learring styles of Greek EFL

students 13-17 and Greek EFL students 18-22.

\section{DEFINITION OF CONCEPTS}

The following seven concepts were used in this study: English as a foreign language, English as a second language, target language, frontisteria, teacher-centered, student-centered and learner-centered.

\section{English as a Eoreign language (EEI)}

English as a foreign language refers to English as it is taught to non-native speakers of English in contexts where the target language (English) is not the predominant language spoken. (For example, in Greece the predominant language spoken is Modern Greek.)

English as a second language (ESI)

English as a second language refers to English as it is taught to non-native speakers of English in contexts where the target language is also the predominant language spoken. For example, in the U.S., where English is the 
predominant language spoken, ESL is taught to non-native speakers of English.

\section{Target language}

The target language refers to the language that is being taught in the classroom. In an EFL classroom, the target language is English.

\section{Erontisteria}

According to Dimaras (1983), Frontisteria are private schools in Greece which concentrate on learning language to pass examinations. Admission to a university in Greece requires the passing of rigorous entrance exams. only top-scoring students are admitted. The elitist nature of the university entrance exams limits the opportunities available for Greeks to earn a college degree. By attending frontisteria, students increase their language ability and their chances of scoring high on these exams and thus of being admitted to the university.

\section{Teacher-centered}

The teacher-centered approach, also known as "traditional", focuses on the teacher, who is viewed as ar authority. Grammar translation and the memorization of 
passages in a book are common activities in a teachercentered language class. Dialogue occurs primarily between teacher and student.

\section{student-centered}

The student-centered approach, also known as the "communicative" approach, focuses on the students, with the teacher acting as a facilitator of language learning. students are encouraged to take a holistic approach to language learning. Activities might include role play between students or group work that requires group members to collaborate on the completion of a task (Enright \& McCloskey, 1985; and Long \& Porter, 1985).

\section{Learner-centered}

The Learner-centered approach considers the needs and preferences of students in curricula planning and classroom procedures. This approach may be either teacher-centered, student-centered, or a combination of both, depending on which style is more effective for the student (Nunar, 1988).

\section{SIGNIFICANCE OF THE STUDY}

This study ascertains what methods of learning Greek EFL students and Greek EFL teachers report they prefer. A study by Reid (1987) examined the learning style 
preferences of ESI students in the U.S. She reported significant differences between the various cultures represented in her sample. This study partially replicates Reid's 1987 study by looking at the reported learning style preferences of Greek students enrolled in EFL classes in Greece. This study also looks at the reported learning style preferences of Greek EFL teachers to see how they relate to the Greek students' preferences. The information this study provides about the learning style preferences of Greek EFL teachers and Greek EFL students may assist EFL instructors interested in working in Greece by suggesting which learning styles the groups in question may respond to more positively. This study also tests Reid's (1987) Ferceptual Learning style Preference Questionnaire (PLSPQ). In addition, it further examines current educational perspectives on the appropriate approaches to teaching English to non-native English speakers.

\section{CULTURAL AWARENESS}

Current courses designed for teaching English to speakers of other languages emphasize the need for cultural awareness on the part of the teachers (Bassano, 1983; Katz, 1988; Little \& Sanders, 1990; Prodromou, 1988). Archer (1986) describes "cultural awareness" as 
the knowledge that people from one culture may behave differently in a particular situation than people from another culture. The classroom is a situation where students from one culture may exhibit different learning styles than students from another. For example, Pia (1989) found that while U.S. students prefer an auditory learning style, Chinese students prefer a visual learning style. With this in mind, a teacher who instructed Chinese students might rely more on printed material than on a lecture format for the relaying of key concepts. Kaplan (1980) discusses how the linear, field independent trinking of English speakers differs from the thought patterns of speakers of other languages. For example, the speakers of semitic languages, such as Arabic, tend to use a logic based on parallel constructions while speakers of oriental languages tend to think in circular patterns. The EFL/ESL teacher who understands where his/her students' thought patterns originate may have more success in interpreting the meaning of their verbal and written messages, thus allowing the teacher to provide the appropriate feedback (Mckay, 1983; Zame1, I984).

Despite their awareness that students from different cultures differ in terms of learning style, Dunn and Dunn (1979) claim that most teachers subconsciously assume that 
the way they personally prefer to learn is also the best way for their students to learn. Hansen and stansfield (1982) explored the significance between students with field independent and field dependent cognitive styles in terms of foreign language achievement. They also included in their study the matching and mismatching of student and teacher cognitive styles. The results of their study implied that the cognitive style of the student played a more important role in determining foreign language achievement than did the teacher's cognitive style or the classroom techniques used.

While Hansen and stansfield (1982) were interested ir the effect of cognitive style on foreign language achievement, a study by Doyle and Rutherford (1984) looked at how the matching of teaching and learning styles affected motivation for learning a second language. Their findings suggested that although the matching of styles had a positive effect on motivation, it had no significant effect on language achievement. Savignon (1991) explains that the current trend toward classroom oriented research responds to the recognition that for many students of a second or foreign language, the classroom is where most of their learning opportunities occur. 
APPROACHES TO LANGUÄGE LEARNING

There are three types of approaches to language teaching commonly referred to in TESCi literature:

1) teacher-centered, 2) student-centered, and 3) learnercentered. The following section distinguishes between these three approaches.

\section{Teacher-centered}

The teacher-centered, or "traditional" language classroom, focuses on the teacher, whom students view as an authority figure or expert (Oxford, 1990; Raimes, 1983; Savignon, 1991). It tends to separate what is taught from how it is taught (Rubin \& Wenden, 1987). According to Quinn (1984) "teacher-centered approaches focus on language as a structured system of grammatical patterns, aim at the production of formally correct. sentences, and concentrate on the form of utterances rather than on the content" (p. 6I). Translation of the target language into the native language and vice versa, audiolingual drills, the memorization of text, and dialogue between studert and teacher, are typical methods used in a teacher-centered classroom. 


\section{Student-centered}

The student-centered, or "communicative", approach to language teaching focuses on the student, with the teacher acting as a facilitator of language learning. This approach received attention with the Council of Europe (Van Ek \& Alexander, 1980; Wilkins, 1976), whose aims were to specify the things that language users might want to do with language used within the European Community. Economic and business activities, as well as recreational and tourist activities, are examples of the functions they addressed. The student-centered approach further gained in popularity with Krashen's (1982) second language aquisition theory and the "natural approach" (Terrell, 1983). Krashen and Terrell both emphasize the importance of language acquisition over language learning. According to Krashen's (1982) affective filter hypothesis, language input that the learner is exposed to must pass through a "filter" before it is acquired. The ability for language input to pass through the filter is affected by such factors as physical environment and anxiety, which may either heighten or lower the affective filter. The lower the affective filter, the easier it is for language acquisition to take place.

Elaborating on Krashen's theory, Terrell (1983) claims that three conditions are required for language 
acquisition to take place. First, the focus needs to be on the message in a commurication situation. Second, the teacher needs to ensure that the learner understands the message by providing comprehensible input (e.g. slower rate of speech, exaggerated intonation, clear articulation). Third, the comprehensible input needs to be received by the student in a low anxiety context (p. 273).

Larsen-Freeman (1986) encourages teachers to decrease the anxiety that second or foreign language learning provokes in certain students so that they may enjoy learning. She contends trat students who enjoy learning are more likely to persist until they reach a level of proficiency in the target language. Physically responding to verbal input (Asher, 1977; Legutke, 1991; Pino, 1989), role play between students, and group work that requires members to collaborate on the completion of a task (Enright \& MCCloskey, 1985; Long \& Porter, 1985) are activities believed to lower students' anxieties, increase their enjoyment of language learning, and thereby lead to greater language learning (Dulay \& Burt, 1985; Krashen, 1982). 


\section{Learner-centered}

Although the terms student-centered and learnercentered are often used interchangeably in regard to second language teaching methods, this researcher uses the terms to describe two different concepts. The definition of learner-centered is modeled after Nunan (1988) who emphasizes the curricular ramifications of the approach.

As previously stated, the student-centered approach to language teaching focuses on the students by directly involving them in activities in which they must communicate using the target language. Not all students, however, prefer to learn in this manner (Farquharson \& Stoynoff, 1990; Horwitz, 1985; and Nunan, 1988). For students who are accustomed to a teacher centeredclassroom where opportunities to communicate verbally in the target language are minimal, a less formal studentcentered context might cause confusion and anxiety (Antier, 1976; Lindsay, 1977) which would be counter to the philosophy that student-centered techniques lower student anxiety.

Like the student-centered approach, the learnercentered approach appreciates the needs and desires of the students. The student-centered teacher encourages students to play a communicative role but does not necessarily consider the students' opinions of that role. 
For the teacher who values the learner-centered approach, however, student needs and desires are the key components of curriculum design and selection of methods (Nunan, 1988; Rubin \& Wende1, 1987).

Raimes (1983) states that the TESOL profession is in the midst of a shift in teaching paradigms which creates a lot of confusion about which method is more effective for foreign/second language achievement. Konstantellou (1990) refers to the confusion resulting from a shift in teaching paradigms as she describes the difficulties of achieving educational reform in Greece.

... A major task for educators and the general public alike is engagement in the debate over the philosophical orientation of Greek education, a debate which will place under scrutiny the appeal to national interest, conserisus, managements, and expertise. (p. 66)

Savignon (1991) interprets the current trend toward classroom oriented research as a response to the conflicting philosophies on teaching methods that abound. The learner-centered approach provides a balance between teacher-centered and student-centered approaches to language teaching.

\section{TEACHING ABROAD}

EFL teachers who are native speakers of English should be informed that their teaching approaches may not 
correspond with the philosophy on teaching methods sanctioned by the education system overseas. Hofstede (1986) warns that teachers who go abroad to teach may be surprised to find an education system that promotes teaching methods thought of as outdated at home. He suggests some adaptation by teachers toward the new system to ensure language teaching success. Native English speaking EFL teachers may find instruments that measure their students' learning preferences useful in their attempts to understand the education system of the new culture.

Reid (1987) claims that identifying the learning style preferences of non-native speakers of English may have wide ranging implications in the areas of curricula design, materials development, student orientation and teacher training. Along similar lines, Nunan (1988) claims that through collaboration with students, teachers could plan curricula that allow for more successful language learning. Both Reid and Nunan relied on self report questionnaires to identify their students' preferences for language learning. After examining their students' preferences, they intended to apply the information to the design of curricula formulated not only by the teachers' perceptions of how students should be 
taught, but in combination with how students report they prefer to learn or be taught.

The author stated in the introduction that a purpose of this study was to familiarize non-Greek EFL teachers, such as herself, with English language study in Greece. In adapting to a new education system, Hofstede (1986) describes four areas in which foreign teachers commonly encounter problems in terms of differences between their native culture and the host culture. They are: I) social positions of students and teachers; 2) curriculum and training content; 3 ) expected patterns of teacher/student and student/student interaction; and 4) cognitive abilities. The following section addresses these four problem areas in a review of the current situation of language teaching in Greece, including analyses of the current system by leading Greek scholars and educators.

\section{THE CURRENT EDUCATIONAL SITUATION IN GREECE}

\section{Greek Ministry of Education}

Andreas Kazamias (1990), a prominent Greek educator, describes the Greek education system as "highly centralized, authoritarian, rigid, formal and paternalistic" (p. 37), suggesting an administration that would value the teacher-centered approach. Education is centralized under the Ministry of National Education and 
Religion which maintains a national uniformity of all curricula, schedules, methods and texts through the use of school inspectors and supervisors. The appointment and promotion of teachers, who are positionally low in the Greek educational hierarchy, is controlled by the ministry (Dimaras, 1983; Kazamias, 1990; Masur, 1985).

\section{Attempts at Educational Reform}

$$
\text { Since the fall of the military junta in } 1974 \text {, }
$$

efforts have been made by educators to reform the Greek education system (Dimaras, 1983; Kazamias, 1990;

Konstantellou, 1990; Kostakis, 1987). Evidence of reform from a teacher-centered to a student-centered (communicative) approach is apparent in a profile on the Greek Ministry of Education's goals related to English language study (British Council, 1986). In 1985, the Greek Ministry of Education revised its goals for Englist language study which was reported in the British Council document as follows:

The 'communicative approach' was adopted by the Ministry of Education as the officially sanctioned methodology for state schools. This is clearly indicated in the aims and objectives of the new Syllabus for English Language Teaching in State Schools. (p. 3)

The revised report explains that under the new policy, heads of schools would have more power when it came to decision making in regard to English language 
teaching. The ministry would make its decisions upon consultation with the center for Educational Studies and In-Service Training, known in Greece as K.E.M.E. (Kentro Ekpaideftikon Melton kai Epimorfoseos). In addition, the document stated that in the secondary schools, stricter requirements were made for students to pass an English course and continue at a higher level. Though the 1986 profile addresses the hope that these ammendments of the requirements for English language study would heighten the status of English language study in Greece, it states that many teachers in Greece are reluctant to employ studentcentered methods.

Implementation of communicative teaching methods is difficult in a country where language teaching is still very traditional, and where teachers (especially head teachers) are generally conservative in their attitude to the communicative methods and to classroom organization and management. (p. 4)

The British Council profile does not emphasize how highly centralized the Greek education system is, nor does it address bow limited the opportunities are for teachers at the lower end of the educational hierarchy to get involved in the decisior making process. Decades of failed attempts at educational reform in Greece (Giimm, 1990; Panourgia, 1990) suggest that Greek teachers are not satisfied with their exclusion from the decision making process. Although the British Council document states 
that K.E.M.E. provides pre-service training for new teachers and increased in-service training for veteran teachers as part of the educational reform efforts, it does not state how the information relayed at these sessions pertains to decision-making processes. Grimm describes the limitations of curricular uniformity as follows:

The system seems to be failing to make full use of a valuable source of ideas and practices for truly energizing, modernizing, and humanizing education that could come from freeing teachers of the bureaucratic barriers to innovation. (p. 92)

Unlike the state-supported schools, the privately operated frontisteria are not bound to a uniform curriculum (British Council, 1986; Grimm, 1990). This does not, however, ensure frontisteria teachers the freedom to choose their own teaching methods. While teaching at a frontisterion in 1993, I was told by the administrator that student-centered teaching methods were preferred. Bearing this in mind, I taught a reading lesson using pairwork, believing the administrator would be pleased with the student-centered activity. I was therefore surprised when the administrator interrupted my class in an attempt to "restore order" by separating students and rearranging the desks into rows. Obviously we did not share the same definition of student-centered methods. 
The results of a study on Greek organizational cultures by Bourantas, fnagnostelis, Mantes and Kefalas (1990) supported findings that Greeks tend to have a high regard for authority (Hofstede, 1980; Triandis \& Vassiliou, 1972). Taking this into consideration, there exists the probability that frontisteria operators have the final say in curricular and methodical decisions.

Literature by Greek EFL teachers on the subject of teaching English as a foreign language in Greece centers on two issues: 1) the failure to keep up with international trends in foreign language teaching, and 2) cultural influences on student motivation for learning a foreign language.

Eailure to keep Up With International Trends

In discussing the current status of EFL in contemporary Greek education, Dandoulakis (1986) suggests that teacher-centered instruction is far more common than student-centered (communicative) instruction in English literature classes in Greece. He reasons that with teacher-centered instruction, students have limited opportunity to actually use their English in an informal communicative setting that is not dictated by the teacher. Contemporary TESOL philosophy maintains that a format that allows students to freely express themselves lessens 
student anxiety and leads to greater langliage learning (Krashen, 1982).

However, Dandoulakis does not explain why a method of instruction sanctioned by the Ministry of Education is used less frequentiy than the formerly endorsed teachercentered approach (British Council, 1982). One way to explain this would be to look at Greek organizations as a whole, which tend to be autocratic (Kazamias, 1990; Triandis \& Vassiliou, 1972). Hofstede's 1980 study of international organizations ranked Greece as number one in uncertainty avoidance, which he defines as "the extent to which people within a culture are made nervous by situations which they perceive as unstructured, unclear, or unpredictable" (p. 310). In his later study on cultural differences in teaching and learning (1986), he describes teachers in strong uncertainty avoidance societies as "considering themselves experts, using academic language and interpreting intellectual disagreement as personal disloyalty" (p. 314). Such characteristics are more akin with the teacher-centered, rather than student-centered, teacher. This may help explain why a Greek EFL teacher might be reluctant to use student-centered methods. Another explanation for the reluctance of Greek teachers to use student-centered methods may be the lack of availability of teacher 
training in the newer methods. Though the British Council report mentions in-service training for teachers. there are reportedly few opportunities for teachers to attend these training sessions (Kazamias, 1990; Konstantellou, 1990).

cultural Influences on student Motivation

Prodromou (1988) alludes to two factors which may negatively affect a student's motivation to learn English. First, he claims that the perception of the Englist language in Greece is full of contradictions. He maintains that in one context it represents power and prestige, while in another it represents the past intervention of English-speaking nations into Greek cultural and political affairs. Though the power and prestige that the English language represents often encourages Greek students to study the language, prejudices toward English speaking people resulting from British and U.S. intervention in Greece, could negatively affect the motivation of Greek students to learn Engliah. Harmer (1983) discusses the factors inside and outside of the classroom that affect a student's motivation to learn English. He uses the term "extrinsid" to describe motivational factors from outside of the classroom, and "intrinsic" to describe motivationai 
factors from within the classroom itself. Examples of extrinsic motivational factors are provided by Prodromou in his discussion of the prestige of the English language in Greece and the influences that the past intervention of English speaking countries have had on the attitudes of Greeks toward the English language. Additional extrinsic motivational factors not addressed by Prodromou come from members of the community in which the student lives, such as parents and peers. Attitudes toward the target language that exist in the student's community subtly affect the student's motivation for learning the target language.

A study that could easily be generalized to Greek EFL students was conducted with the parents of Canadian children studying French as a second language (Gardner, 1978). Parents were categorized as having an active and/or passive role in their children's degree of success in learning French. In playing an active role, parents consciously encouraged their children to learn by seeing that their homework was completed and by praising their children's success. In the passive role, parents influenced their children subtly through their negative attitudes toward the French. Gardner concluded that those parents who gave passive encouragement had less motivated children than those parents who gave active encouragement. 
For example, those parents who had negative attitudes toward French undermined any encouragement they gave their children to study the language and were considered passive. The children of parents with positive attitudes toward the French were found to be the most highly motivated to learn the language.

The British Council (1986) report on Greece lists the role of the parents as a strength in the English language teaching situation in Greece. From Gardner's perspective, the Greek parents would be described as playing a very active role in their children's education. This is evident in the value that is piaced on education, the discipline that is maintained at home in seeing that homework is completed, and the long hours that Greek parents have their children spend in the classroom by sending them to private frontisteria in addition to the state supported schools.

Though Prodromou does not make a direct correlation between parents' attitudes toward English and the child's motivation to ?earn, his discussion of the negative attitudes toward Englist speaking people that prevail in Greece suggest that such factors may affect the students' motivation to learr.

The second area that prodromou claims may negatively affect a student's motivation to learn English is the 
classroom setting. He maintains that English textbooks available in Greece culturally alienate students by failing to include images that are culturally relevant to Greece (e.g. illustrations of British school boys, the prevalent use of English proper nouns). He suggests that visiting instructors are often insensitive to the alienation that EFL students feel toward the English language and the cultures of those who speak it as a native language.

In a more recent article which prodromou based on a survey of Greek EFL students' beliefs on language learning (1992), the majority of students believed their foreigr teachers should have some knowledge of Greek culture. Frodromou suggests that by becoming more aware of Greek culture, EFL teachers who are natives of English speaking countries may reduce some of the alienation their students feel toward the English language and the cultures of the people who speak it.

Although Prodromou concentrates on the visiting English teacher's effect on Greek students' motivation to learn, four out of every five teachers hired in Greece are required to be Greek nationals. Harmer (1983) states that the EFL teacher who is a non-native speaker of English may affect the students' motivation to learn the target 
language through their opinions of the language and the people who speak it as a native language.

If the teacher is negative about the culture of the target language this will be disadvantageous, and it is equally true that a positive attitude towards the culture (by which we do not mean uncritical) will help. (p. 4)

Prodromou raises an important issue about the students' opinions of their Greek EFL teachers? How important is it that they know about the culture of the target language and to what extent does it affect their motivation for learning English?

ESL STUDENTS IN THE U.S.

\section{Eactors Interfering With hanguage Learning}

Although Prodromou and Dandoulakis stress the need for different language teaching methods, whenever a relatively new teaching method is introduced into the EFL classroom it is accompanied by a certain level of anxiety. Alsop, (1979) suggests that teachers can allow for more success in using communicative activities with their students if they first measure the teaching methods that may cause the most anxiety for their students, and are therefore more likely to interfere with learning.

As a step toward learner-centered methods, various studies have been conducted with ESL students to determine which methods are associated with the most anxiety and 
also which methods are preferred. Eassano (1983) explored in-class emotional negativity, which she described as poor motivation, anxiety about speaking in the target language and uncertainty about the effectiveness of studentcentered teaching methods. Bassano's findings incicated that ESL students desire more teacher-centered instruction. Of the students who preferred teachercentered instruction, $90 \%$ believed this would allow them to speak English like a native speaker of the language. Traditional teacher-centered methods rely on pronunciation drills, memorization, and error correction in an attempt to reach language perfection. The ability of such methods to accomplish a goal of language perfection remains questionable.

Menyuk (1983) discusses several critical ages for the acquisition of various language skills, such as the pronunciation of particular phonemes, or the mastery of certain grammatical elements. The last of these stages ends in late adolescence. According to Menyuk (1983), once we become adults we lose most of our natural ability to acquire language. He estimates that as few as 58 of adults can achieve native-like mastery of a foreign language. Johnson and Newport (1989) further elaborate on the issue of a critical period for language learning, by claiming that adults who mastered a second language before 
reaching puberty have a much greater chance of achieving rative-like mastery in any subsequent languages learned. since schools tend to introduce students to foreigr language study at or beyona puberty, they would have a lessened chance of reaching native-like mastery of the target language. This is discouraging news when one considers that a reported $90 \%$ of adult ESL language learners feel language perfection is a reasonable goal.

No studies have been done on the percentage of Greek EFL students who believe perfection in English is a reasonable goal. One can only surmise that students and teachers who prefer teacher-centered methods may consider language perfection in English a possibility. Accordingly, a student with high expectations of reaching native-like fluency in the target language may perceive imperfection as failure, increasing his/her anxiety about performing in the target language.

If both teacher-centered and student-centered methods arouse student anxiety, what methods should an effective EFL/ESL teacher employ? Katz (1988) explored what makes an "effective teacher" by having students write compositions on the topic. "Being able to explain things" headed the list of what makes an effective teacher. One of the complaints students have about the student-centered classroom is they are not sure of what they are supposed 
to be doing, nor of the role of communicative activities in learring a foreign language. Nuran (1991) encourages teachers to take the extra measure of explaining to students what they are about to experience. Taking this extra measure ahead of time might assist in alleviating some of their fear about performing. Lessening their anxiety would likewise contribute to greater language learning by lowering the affective filter that allows for language acquisition (Krashen, 1982; Krashen \& Terrell, 1983; Larsen-Freeman, 1986).

Curriculum Development and self-report questionnaires

Nunan (1988) encouraged teachers to use "needs analyses" in the form of a survey questionnaire to determine what students want to learn. Once teachers analyzed their students' responses, they would design curricula based on the interpreted needs of those students in question. While Nunan (1988) explored what students believe they need to learn, Reid (198?) investigated how students prefer to learn because of the "wide-ranging implications it would have in the areas of curriculum design, materials development, student orientation and teacher training" (P. 88). Reid adapted the C.I.T.E. (Center for Innovative Teaching Experience) Learning Styles Instrument (Babich, Burdine, Albright \& Randal, 
1975) to identify the preferred perceptual learning styles of non-native zpeakers of English.

Keefe (1982) identifies three categories of learring styles: cognitive, affective, and physiological. He defines them as "traits that are relatively stable indicators of how learners perceive, interact with and respond to the learning environment" (p. 4). Perceptual learning styles fall under the cognitive category of learning styles and refer to the variety of ways individuals use the senses to process, organize and remember information or experiences. Regardless of the content learned, Fischer and Fischer (1979) claim that the individual's learning style remains stable.

The implications of identifying the students's learning style is that the teacher may better address the learning needs of the student. Researchers assert that the matching of teachers' and students' learning styles can have a positive effect on the students' motivation to learn (Dunn \& Dunn, 1979; Hansen \& Stansfield, 1982), which is believed to lower anxiety and lead to greatei language acquisition.

Reid's survey, the perceptual Learning style Preferences Questionnaire (PLSPQ), queried 1,388 students on two categories of learning styles: perceptual learning which includes vistial, auditory, kinesthetic and tactile; 
and group oriented learning which includes group and individual. The sample consisted of 154 native speakers of English, and 1,234 ESL students representing eight language groups.

Reid adapted her descriptions of the four perceptual learning styles: visual, auditory, kinesthetic and tactile; from studies by Reinert (1976) and Durn (1984). Reid listed reading, studying charts, and visualizing objects in her definition of the visual style of learning. She included listening to lectures, audiotapes, and discussions as examples of the auditory learning style. Reid defines kinesthetic learning as experiential learning, typified by total physical involvement with the learning situation, such as drama, role-play and physical response to verbal requests. Whereas kinesthetic learring implies total body involvement, Reid uses terms such as "hands on" learning and the manipulation of objects to describe tactile learning. Art projects and board games are examples of tactile learning. The remaining two learning styles, group and incividual, refer to whether or not a student prefers to learn collaboratively in groups, or individually, without assistance from classmates. Visual and auditory learning tend to call for a passive student role. As with individual learning, these styles do not require interaction with fellow classmates. 
These characteristics conform more with a traditional teacher-centered approach to learning than with a studentcentered approach. The following two learning styles, however, kinesthetic and tactile, promote an active student role, as in the student-centered approach. Group work invoives ccliaboration with fellow students, and therefore it also suggests a student-centered approach to language learning.

Using a five-point likert scale, subjects were asked to mark one of five choices ranging from "strongly agree" to "strongly disagree." A response of "strongly agree" would earn five points, whereas a response of "strongly disagree" would earn one point. After the questionnaires were completed, the scores for each learning style were totaled. The students' scores for each learning style ranged from 0 to 50 . Item scores in the 0 to 24 range indicated a "negligible" learning style, meaning the style was not favored. Scores from 25 to 37 she 1 abeled as "minor", denoting a style that was moderately favored. Third, scores ranging from 38 to 50 were listed as major learning atyles, implying they were overwhelmingly preferred over other styles. According to keid's guidelines, if a student identified kinesthetic learning, e.g., physically involving oneself in the learning experience, as a major 
learning style, the teacher might expect that student to respond well to Total Physical Response (Asher 1977). Asher's method calls for students to physically respond to prompts given by the teacher in the target language. For example, if a teacher instructed a student to "open the door" or "erase the blackboard", the student would physically complete the task in order to exhibit his/her comprehension of the cue.

The results of Reid's study found that the majority of participants reportedly preferred to learn kinesthetically and tactilely, learning styles more commonly associated with student-centered rather than teacher-centered teaching methods. With correlation coefficients between .63 and .88 , Reid's 1987 study was not particularly high in reliability. This could, however, be attributed to the varying cultures her sample represented. The study included the following nine language groups: Arabic, Spanish, Japanese, Malay, Chinese, Korean, Thai, Indonesian and English. Studies of thought patterns across cultures suggest that differert modes of thinking are culture specific (Kaplan, 1980; Wilkin, 1976). If one group indicated a particular learning style as negligible and another group reported the same style as major, the mean of the two scores 
probably would be minor, even though this was rot the case with either group.

Reid also examined the effect of age on learning style preference. The results of a study by oxford and Nyikos (1989) found that young adult students frequently reported employing formal rule-related practice strategies likely to be used in a traditional, structure-oriented, foreign language classroom. They tended to disfavor strategies which emphasized communication and language function over structure.

Harmer (1983) claims that adults come to class with a high level of extrinsic motivation. Although strategies which emphasized communicating in the new language were shunned by most of the students in their sample, oxford and Nyikos (1989) found that the higher the student's motivation, the more likely he/she was to respond positively to a variety of language learning strategies. Although Reid's study did not reveal significant differences based on age, Reid found that the older the student, the higher his/her preference means for all four perceptual learning styles: visual, auditory, kinesthetic and tactile.

In addition to culture and age, Reid examined the relationship of gender on learning style preference. oxford and Nyikos (1989) found that gender had a profound 
effect on the choice of learning strategies. Among the participants in the study, females reported a significantly greater use of conversational input and learning strategies reflecting social interaction than males. Among the participants in Reid's study, males reportedly preferred visual and tactile learning styles significantly more than females.

Pia (1989) and Hoffner (1991) tested the reliability of Reid's study by conducting culture-specific studies with Chinese ESL/EFL and Japanese ESL/EFL students, two language groups represented in Reid's study. Hoffner's (1991) sample of Japanese ESL/EFL students reported oniy minor learning styles, adding support to Reid's findings on 130 Japanese students. Pia (1989) concluded that the majority of Chinese participants in his study preferred to learn visually, contrasting with Reid's findings on the preferences of 90 Chinese ESL students. Pia also explored the effect of gender on learning style preference. His findings indicated that chinese males favored individual learning significantly more than chinese females. Furthermore, Chinese females preferred kinesthetic learning significantly more than chinese males. The inconsistency between Pia's and Reid's findings suggest that further culture specific studies on preferred learning styles need to be conducted. 
The current study on the learning style preferences of Greek students and teachers of English as a foreign language further tested the reliability of Reid's 1987 study. In addition to the variable of Greek culture, it also looked at the variables of occupation (studert/teacher), age and gender in interaction with learning style preference.

In reference to occupation, this researcher expected the students in this study to prefer styles associated with the teacher-centered approach, such as visual, auditory and individual learning. This prediction is based on the perceived compatibility of the authoritarian nature of Greek society with the teacher-centered approach in which the teacher is viewed as an authority figure. The teachers in this study are expected to prefer styles associated with student-centered teaching methods, such as kinesthetic, tactile, and group learning, in consensus with the Greek Ministry of Education, which ratifies student-centered methods.

Reid's results corroborated Oxford and Nyikos (1989) findings on preferred learning strategies for age and gender. Little of the research pertaining to English language study in Greece directly addresses the effects of age and gender on language learning. 
Sakta-Paraskeva (1984) reports that the resuits of a personality test administered by Kokkevi, Typaldou, Repapi, Adamou and stefanis (1981) indicated significant interaction effects between both age and gender. Seddon, Papaioannou and Fedrosa (2990) administered three sets of questions in both witten and oral form to science students in Greece and Fortugal to ascertair whether the format had an effect on student achievement. A secondary aim of the study was to determine whether the variables of age and gender affected performance. However, their findings revealed no statistically significant interaction effects in correspondence with age and gender.

Despite the inconclusive findings of seddon et al (1990), the expectation for the current study was that there would be a significant difference in learning style preference in relation to age and gender of Greek EFL students. The researcher based her assumptions on similar repozts on cognitive styles (Hanser \& Stansfield, 1982), learning and teaching strategies (Horwitz, 1985; Oxford \& Nyikos, 1989) and learning style preferences (Pia, 1989; Reid, 1987).

Horwitz (1985) claims that "students' previous experiences influence their opinions of language learning methods (p. 335)" and that they tend to favor the methods that they are the most familiar with. The Greek Ministry 
of culture sanctioned the student-centered approach to English language teaching in 1985, when the oldest of students in the 13 to 17 year-old age group would have just begun to study English. The students in the 18 to 22 year-old age group would have already experienced learning with some of the previously endorsed teacher-centered methods. Therefore, according to Horwitz (1985) the early exposure of students in the older age group to teachercentered methods may have resulted in their having preconceived notions that teacher-centered methods are superior.

It is hypothesized that strong differences in gender roles in Greek society may affect learning style preference. Dimaras (1983) and Massur (1985) assert that the maintenance of family honor in traditiona! Greek society depends on the complementarity of male and female roles. For example, the female ideally dominates in domestic and spiritual matters, while the male ideally dominates in business and official matters. The assumption is that this division of appropriate male and female tasks may have an effect on the preferred learning style of Greek males and Greek females. Perhaps these different roles have an effect on how they are treated by the teacher in a classroom. 
Kostakis (1987) examined the achievements of ninth grade Greek students enrolled in physics and literature course and determined that gender was second only to parental education in its effect on scholastic achievement. Frevious studies in the foreign language classroom have revealed that males and females tend to differ in terms of the learning strategies they choose (Hosenfeld, 1979; Kramarae, 1981; Oxford \& Nyikos, 1989). The results of these studies added to the expectation of gender differences and preferred learning style.

In recognition of the paradigm shift from teachercentered to student-centered teaching, this researcher classified the six learning styles included in the PLSPQ as either teacher-centered or student-centered. She based her decision of which learning styles were most appropriate for either teaching style on descriptions of learning styles and teaching methods characteristic of the student-centered approach (Asher, 1977; Dulay \& Burt, 1985; Enright \& MCCloskey, 1985; Long \& Eorter, 1985) and those representative of a teachercentered approach (oxford, 1990; Quinn, 1984; Rubin \& Wenden, 1987). 
SUMMARY

An assumption had been made that by identifying learning style preferences reported based on the cultural background of the students, Nunan's (1988) call for student involvement in curriculum design wohid be easier to accomplish. In recognizing the diversity that exists among education systems and culturaliy encouraged thought patterns, this culture specific study looked at the learning style preferences of Greek students and Greek teachers of English as a foreign language in a private language institution. The researcher conjectured that the subjects' reported preferences would be generalizable to students and teachers of similar ages at similar langliage institutions, (Greek frontisteria).

This chapter identified the classroom as a situation in which individuals in one culture may behave differently than another. The alithor recognized that her U.S. perspective on appropriate teaching methods and classroom behavior might differ from the Greek perspective. One section of her literature review alluded to the current situation of English language teaching in Greece to illustrate what Greeks consider a suitable language learning environment. 
The Greek education system was described as centralized through the Greek Ministry of Education and Religion (Massur, 1985; Kazamias, 1990; Panourgia, 1990). The portrayal of hierarchically distributed power expands Hofstede's (1980) findings that Greek culture is extremely authoritarian. Despite the hierarchical manner in which the Ministry handies its educational decisions, it endorses a student-centered (communicative approach) to language learning (British Council, I986). Dandoulakis's (1986) claim that Greek EFI teachers rely too much on teacher-centered methods, combined with the British Council's (1986) statement that Greek teachers are reluctant to use student-centered methods, further confuses the issue of the student-centered approach in Greece.

Studies in ESL classrooms in North America and Australia have explored students' opinions of studentcentered teaching methods (Bassano, 1983; itttle \& Sanders, 1990; Nunan, 1988) and have elicited responses ranging from severe anxiety to concern about the effectiveness of the innovative student-centered methods. Researchers in the TESOL field have discussed how anxiety can negatively affect motivation for learning and achievement in the second language (Harmer, 1983; Krashen \& Terrell, 1983; Firo, 1989). The remaining question was 
in connection with Greek EFL students' and teachers' preferred styles of learning and teaching and whethe: or not these preferences could be accurately measured.

Although studies on the subject of English language teaching in Greece have measured personality (SakkaParaskeva, 1984) and beliefs about the role of culture in the classroom (Frodromou, 1992), no previous studies have been conducted on the learning style preferences of Greeir EFL students. Both Greek EFL students and Greek EFL teachers were included in this study so that their learning style preferences might be compared. Teachers often subconsciously assume that the styles with which they learn best are effective styles for their students as well (Hansen \& Stansfield, 1982; Horwitz, 1985; Oxford \& Nyikos, 1990). Comparing the preferences of Greek EFL students and teachers would clarify whether or not their learning styles matched.

Reid (1987) focused on different culturai groups in her study of the preferred learning style preferences of ESI students in the U.S. This researcher expanded on Reid's study by including Greek EFL students and Greek EFL teachers. Not only would subjects' learning style preferences be identified, information would be gained useful in designing a learner-centered curriculum. A learner-centered curriculum could address the controversy 
surrounding the state mandated student-centered curriculum in Greece by allowing for teacher-centered methods when it is in the best interest of the students. 
CHAPTER II

\section{METHODS}

The purpose of this study was to identify the learning style preferences of Greek teachers and Greek students of English as a foreign Ianguage in the Greek cuitural context. This exploratory field study used quantitative measures to identify the learning style preferences of both Greek students of English as a foreign language, and Greek teachers of English as a foreign language. The following sections describe these procedures.

\section{SAMPLING FRAME}

For purposes of this study, the sampling frame was Greek EFL students and Greek EFL teachers in Greece. Subjects were recruited through the cooperation and agreement of the Eapaeiiou School of English. The researcher contacted the Iirector of studies orally, asking for her permission to conduct this study at the Papaeliou school which is situated in Piraeus, Greece. The director of studies granted the researcher's request 
oraliy, then iater confirmed her agreement in writing (see appendix $H$ ).

The Papaeliou School of English was founded by Panayiotis Papaeliou, a prominent Greek educator, in 1955 , and continues under the administration of his two daughters. The school offers general English courses to students of all ages. In addition, it provides teacher training courses for individuals who intend to teach English as a foreign language. Rather than follow a traditioraliy conservative method of teaching, the Papaeliou school emphasizes the adaptation of teaching methods to the specific needs of the students, a perspective congruent with a learner-centered curriculum. It should be noted that the Papaeliou school falls under the classification of frontisterior. According to Dimaras (1983), frontisteria are private schools which concentrate on examination subjects. Because of the elitist nature of university entrance exams, Greeks often pay to attend frontisteria in order to increase their chances of achieving high marks on these exams. Though the Eapaeliou school is limited to the study of English, not ali frontisteria are restricted to foreign language study. Furthermore, while the Papaeliou school offers courses that prepare its students for all English language tests available in Greece, such as the Cambridge and 
Michigan Proficiency tests and the TOEPi (Test of English as a foreign language), a large number of ztudents attend the school for the personal edification of learning a foreign language.

Unlike the state schools, in which students receive a maximum of three 45 minute segments of instruction a week, regular courses at the Papaeliou school meet four to seven hours a week. Intensive courses meet for as much as 15 hours a week. Another difference between state supported schools and the Papaeliou school is that teachers at the state supported schools must follow the student-centered curriculum mandated by the Ministry of Education, while the Papaeliou school allows its teachers to choose their own methods based on the perceived needs of the students. Owing to the number of hours that students at the Papaeliou school meet, as well as to the Elexibility that its teachers are allowed, this researcher determined that the Papaeliou students were likely to have been exposed to all the learning styles mentioned in the questionnaire.

All subjects were born and raised in Greece and had studied English at least six years. All student participants were enrolled in preparatory courses for the Michigan Test of English Language Proficiency. The Fapaeliou School's description of courses states that its 
teachers employ both student-centered and teacher-centered instructional methods. Based on the school's description of courses, the researcher determined that the students would have experienced learning in all six of the learning styles included in the questionnaire, and therefore would be $a b l \in$ to accurately respond to the statements provided.

The student subjects were divided into two groups: 33 Greek adolescents ages 13 to 17 , and 59 young adult Greeks ages 18 to 22. The reason for the breakdown of ages was that students 13 to 17 would require their parents' consent in order to participate in the study. Age groups were unrelated to level of language proficiency as there is no prescribed age for which students in Greece begin their foreign language study. However, the researcher considered that there might be some variation in the learning style preferences between students.

The teachers who participated in the study were all of Greek nationality and were all employed by the Papaeliou School of English. The researcher included them in the study in order to conduct a comparative analysis between students' and teachers' reported learning style preferences. 
SAMPLE

The non-random convenience sample consisted of 92 EFL students and 11 EFL teachers from the papaeliou school of English in Piraeus, Greece. The administrators of the questionnaires orally informed the researcher that 103 of the 170 subjects contacted agreed to participate in the study. The student sample consisted of 17 Greek teenage boys and 16 girls, $13-17$ years of age, and 16 young adult Greek men and 43 women. 18 to 22 years of age. The teacher sample consisted of three Greek men and eight women, ranging in age from 22 to 52.

\section{MEASUREMENT}

This study is a partial replication of Reid's 1987 survey on the learning style preferences of ESL students in which a quantitative method of research was employed. The instrument, the Ferceptual Learning style preference Questionnaire (PLSFQ), was developed by Reid. She modeled the questionnaire after the center for Innovative Teaching Experience learning styles instrument (CITE, Babich et al, 1975) with adaptations made for non-native speakers of English. 


\section{Instrument}

The Perceptual Learning style preference

Questionnaire (see appendix $C$ ) is a 30 -item questionnaire consisting of five statements representing each of the six learning styles to be measured: 1) visual - learning by seeing information in print; 2) auditory - learning by listening to information conveyed; 3) kinesthetic learning by becoming physically involved in the learning experience; 4) tactile - learning by "hands on" experience with materials; 5) group - learning by group collaboration or tasks; and 6) individual - learning by studying information alone.

Using a five-point Likert scale, subjects were asked to marle one of five choices ranging from "strongly agree" to "strongly disagree" (see appendix C). In the Greek translation of the survey, "strongly agree" and "strongly disagree" were changed to "absolutely true" and "absolutely untrue", as the Greel: language does not differentiate between "strongly agree" and "agree". Likewise, there is no differentiation between "strongly disagree" and "disagree" in Greek. Directions on the survey expiained that people learn in different ways, and that the purpose of the questionnaire was to identify the way that students and teachers prefer to learn. Fn example of a particular learning style was cited with a 
choice made on the scale. An explanation of some of the terms in the questionnaire such as "doing somethina", "role play" and "make a model" was provided. As experienced during a pilot study conducted of native Greeks living in the U.S. (see p. 39) and as reported by the administrators of the questionnaire at the Papaeliou school, completion of the questionnaire took approximately 15 to 20 minutes.

\section{Validity and Reliability}

Reid validated her instrument by the split-half method and a correlational analysis of 60 statements determined which 30 would be used in the questionnaire. Correlations were between .63 and .88 , and although they were not as high with ESL students as with native speakers, Reid attributed this to the varying backgrounds of her study sample (e.g. Arabic, Spanish, Japanese, Malay, Chinese, Korean, Thai, and Indonesian). It is anticipated that reliability should be higher in the current study because of the subjects' similar cultural backgrounas.

\section{Demographic Data}

Demographic information was collected using an adaptation of the form used by Reid (1987). The originai form was designed with ESL students in mind, and included 
such information as TOEFL score and length of time in U.S. Such information was not applicable to this group. For this particular study modifications were made for EFL students and teachers (see Appendix $C$ ). This was attached to the actual questionnate.

\section{RESEARCH PROCEDURES}

\section{Translation Erocedure}

The instrument, cover letters and consent forms were translated into Modern Greek by a native Greek who is proficient in the English language. These translations were then backtranslated by another native Greek who is equally competent in English (see appendix E). Although the backtranslation was not a duplicate of the original, the researcher was confident that the meaning of the criginal had been preserved. The translation of the questionnaire into Greek ensured that language would not present a barrier to understanding. As stated in the description of the instrument, slight modifications were necessary to ensure cultural understanding by participants. For example, in order to keep a five-point Likert scale, absolutely true and absolutely untrue were substituted for strongly agree and strongly disagree. 
Dilet study

A pilot study was conducted of native Greeks to test the reliability of the Greek transiation of the questionnaire. The subjects were all adults who had studied English as a foreigr language ir Greece. Eased on the pilot study, in which confusion arose regarding terms used in questions $2,8,11$, and 19, modifications were made to the questionraire in the form of a more detailed explanation of terms. The confusion which arose from the terms used may be attributed to the ambiguous meaning of the terms when translated into Greek.

The following modifications were made. The terms "doing something" and "doing things" used in questions 2 and 8 were further explained as being physically involved or actively participating in an activity. Going on a field trip or acting out dialogues were given as examples of "doing something." "Model," a term used in question II was further explained as actually making something with information received. Diagrams and graphs were given as examples of "models." The last of the terms, "role play," was further explained as playing the part of a character.

Data Collection Procedure

The researcher contacted Mc. Papaeliou, director of studies at the Papaeliou school, after a member of Ms. 
Papaeliou's "ingroup" suggested that the researcher use the school as the research site. In Greece, irgroup members consist of family, friends, friends of friends, and people who show concern (Iriandis et al., 1968). In this situation, the ingroup member was a friend of both Ms. Papaeliou's and the researcher's. This most likely placed the researcher in Ms. Fapaeliou's ingroup by virtue of their mutual friend. The researcher initiated communication with the director of studies by telephone and asked for her permission to conduct the study at the Papaeliou school. The director of studies agreed, then faxed the researcher official written consent isee appendix $\mathrm{H}$ ).

The translated questionnaire and consert forms were then sent to the school (see appendix D). The teachers of the stuaents who consented to participate, agreed to provide class time for the completion of the questionaire. The teachers at the Fapaciou School who agreed to participate completed the questionaire in their own free time at the school. All participants were given a cover letter explaining the study and were requested to read and sign the informed consent (see appendices $A$ and B). The letter tharked the subjects for their participation in the research and briefly described the purpose of the study. It assured the confidentiality of 
all who took part in the survey and informed them of their right to withdraw from the study at any time. In additicn, a letter was sent to the parents of all students under 18 years of age (see appendices $A$ and $B$ ), requesting parental approval for their children's taking part in the survey. The completed questionnaires were returned by mail to the researcher in the United states. The data were collected during December of 1992.

The current research was not conducted pursuant to a contract or grant, and had not been reviewed before. This research was not exempt from HSRRC review. Upon review by HSRRC, the research was approved (see appendix F). While the subjects in the study were not anonymous to the researcher, their identities were kept confidential. Data was coded as group data. In this way, information from the study could be kept on file without violation of confidentiality.

\section{DATA ANALYSIS}

The demographic data collected included occupation (student or teacher), gender, and age. The data collected were then analyzed for preference of the six learning styles. A paired t-test was conducted for teachers' and students' preferences for teacher-centered (visual, auditory, and individual, and student-centered 
(kinesthetic, tactile, and group) learning styles. Six linpaired t-tests, one for each of the six learning styles. icentified significant differences between the mean scores of teachers and students.

Two two-factor Anovas, one for gender and one for age, identified significant differences between the subgroups of male and female students, and the subgroups of students in age from 13 to 17 and 18 to 22 . In the case where a significant difference was found, as was the case with the two-factor Anova for age, six single-factor Anovas, one for each of the six learning styles, were performed. 
CHAFTER III

\section{RESULTS}

The data analyzed from the self reporting surveys (see appendix I) are reported in this chapter. The first section identifies the preferied learning styles of two groups: Greek EFL students, and Greek EFL teachers. It then analyzes the styles for significant differences. The second section analyzes the differences among the student subgroups. This section of the chapter presents the relationships betweer learning style and the variables of gender and age. The expectation for this study was that there would be significant differences in the preferred learning styles of the two main groups, students and teachers. It was also expected that there would be significant differences between the subgroups of male and female students, and the subgroups of students 17 and younger and students 18 and older.

\section{GREEK EFL TEACHERS AND GREEK EFL STUDENTS}

\section{combined scores of Teachers and students}

Upon completion of the questionraires, each response was assigned a numerical value ranging from 1 to 5. Total points were compiled for each of the six learning style 
categories using the scale attached to the end of the questionnaire (see appendix $C$ ). This scale determined the subjects' major, minor and negligible learning style preferences. The preferred learning styles of a group were identified by the mean score established for each of the six learning styles (visual, auditory, kinesthetic, tactile, group and individual). The mean scores were classified as major, minor, and negligible. Reid established the following guidelines for interpreting the mean scores:

$$
\begin{array}{lc}
\text { Major Learning Style } & 38-50 \\
\text { Minor Learning Style } & 25-37 \\
\text { Nealigible Learning Style } & 0-24
\end{array}
$$

The scores of the teachers and students were combined to show their range. The combined scores of the two groups shown in TABLE I indicate mean scores between 30.64 and 38.14 for the six styles addressed by the survey.

Mean scares for Greek EFL Leachers and Greek EFI Students

Table I shows the mean scores for both the Greel: EFL teachers and Greek EFL students. Based on Reid's standards for identifying a score as either major, minor, or negligible, the teachers identified three major learning styles and three minor learning styles. No negligible learning styles were reported by the teachers. 
The major learning styles the teachers identified were visual, with a score of 38 ; kinesthetic, with a score of 42.55; and tactile, with a score of 41.27 .

The Greek EFL students reported primarily minor learning styles with one exception. The students' average score for kinesthetic learning was 37.61 (.39 shy of being considered a major learning style). If one were to round this figure off-it would round off to 38 , which is considered a major learning style. This researcher therefore suggests that the Greek EFL students exhibit a tendency toward kinesthetic as a major learning style. As with the Greek EFL teachers, the Greek EFL students reported no negligible learning styles.

\section{TABLE I}

COMBINED SCORES OF TEACHERS AND STUDENTS

\begin{tabular}{|ccccccc|}
\hline & V & A & K & T & G & I \\
Min. & 20 & 20 & 16 & 20 & 12 & 14 \\
Max. & 50 & 46 & 50 & 50 & 50 & 50 \\
Mean & 36.1 & 35.17 & 38.14 & 35.48 & 30.64 & 33.63 \\
\hline
\end{tabular}

$\mathrm{N}$ of cases $=103$
$v=$ visual
$K=$ kinesthetic
$G=$ group
$I=$ auditory
$T=\operatorname{tactile}$
$I=$ individual 
The level of significance for this study was set at $p<.05$, the normal level of significance for social science research (Sproull, 1988). To test for teachers' and students' preferences for learning styles in terms of teacher-centered and student-centered learning styles, a paired t-test was conducted. The mean scores of the students' teacher-centered and student-centered scores, which fell in a normal distribution, were paired in order to see if there was a significant difference between the two scores. Student-centered, which refers to kinesthetic, tactile and group learning, was represented by the variable $x$. Teacher-centered which refers to visual, auditory and individual learning, was represented by y.

As shown in Table III, the probability value of the students' paired $t$ value was -.53 , indicating a slight preference for teacher-centered learning styles. These results did not support the hypothesis that Greek EFL students prefer teacher-centered learning over studentcentered learning. The result of the teachers' paired $t$ value was .98, indicating a slight preference for studentcentered learning. But again, these findings did not support student-centered styles as a preference for teachers. 
TABLE II

MEAN SCORES FOR EFL TEACHERS AND EFL STUDENTS

\begin{tabular}{|ccccccc|}
\hline & V & G & K & T & G & I \\
Students & 35.87 & 35.04 & 37.61 & 34.78 & 30.41 & 33.22 \\
$\mathrm{n}=92$ & & & & & & \\
Std. Dev. & 6.45 & 5.46 & 7.09 & 7.12 & 8.40 & 9.43 \\
Teachers & 38 & 36.18 & 42.55 & 41.27 & 32.55 & 37.09 \\
n $=11$ & & & & & & \\
Std. Dev. & 7.38 & 5.1 & 4.91 & 6.40 & 6.99 & 11.88 \\
\hline
\end{tabular}

TABLE III

PAIRED T-TEST FOR PREFERENCE MEANS OF

STUDENT-CENTERED AND TEACHER-

CENTERED LEARNING STYLES

\begin{tabular}{|ccccc|}
\hline & DF & Mean X-Y & Paired $t$ Value & $p<.05$ \\
Students & 91 & -.44 & -.53 & .5949 \\
Teachers & 10 & 1.7 & .98 & .3485 \\
\hline
\end{tabular}

$X=$ Student Centered Average

$Y=$ Teacher Centered Average

Six unpaired t-tests, one for each of the six learning styles, were performed to test for significant differences between the mean scores of teachers and students (see Table IV). Comparisons of the two groups 
indicated significant differences occurring in their responses to kinesthetic learning $(s<.05)$, and tactile learning $(p<.01)$. Although both groups identified kinesthetic iearning as a major iearning styie, the resuits indicate that the teachers prefer kinesthetic learning more than the students.

TABLE IV

UNPAIRED $t$-TEST FOR STUDENT MEAN SCORES

AND TEACHER MEAN SCORES

\begin{tabular}{llcccccc|} 
& V & A & K & $T$ & $G$ & $I$ \\
& & & & & & \\
Teacher Mean: & 38 & 36.18 & 42.55 & 41.27 & 32.55 & 37.09 \\
Student Mean: & 35.87 & 35.04 & 37.61 & 34.78 & 30.41 & 33.22 \\
DF: & 101 & 101 & 101 & 101 & 101 & 101 \\
T-value: & 1.02 & .66 & 2.24 & 2.88 & .81 & 1.25 \\
P<.05: & .31 & .5124 & $\star .0271$ & $\star .0048$ & .4212 & .2135 \\
\hline
\end{tabular}

* Indicates significance at $p<.05$ level

SUBGROUPS OF GREEK EFL STUDENTS

The second section of this chapter examines the subgroups drawn from the student population. Whereas the first section of this chapter analyzed data from the student group as a whole, this section examines the data by gender and by age. Because of the limited teacher 
population, no subgroups were examined from within that group.

Gender

The first two suigroups, male and Eemale students, were compared to see if the relationship of learning style and gender revealed any significant difference. Displayed in Table $V$, the mean scores for both male and female students indicate that kinesthetic learning was on the cusp of being a major learning style for both genders. As with the mean scores for the entire student population, all other learning styles were identified as minor learning styles. No negligible learning styles emerged for either gender.

TABLE V

MEAN SCORES FOR MALE AND FEMALE STUDENTS

\begin{tabular}{|lcccccc|}
\hline & V & A & K & T & G & I \\
Female & 35.2 & 34.88 & 37.63 & 34.88 & 30.1 & 33.36 \\
$\begin{array}{l}n=59 \\
\text { Std. Dev. }\end{array}$ & 5.57 & 5.27 & 6.34 & 6.92 & 8.08 & 8.66 \\
Male & 35.27 & 35.33 & 37.58 & 34.61 & 30.97 & 32.97 \\
n $=33$ & 7.84 & 5.87 & 8.36 & 7.57 & 9.06 & 10.81 \\
\hline Std. Dev. & 7.84
\end{tabular}

A test for significant differences between the sub- 
groups of males and females, a two-factor Anova, revealed no significant difference in mean learning style preferences $(p<.001)$ for interaction with the variable of gender (see Table VI). Since no significance was found, there was no need to perform further tests.

TABLE VI

TWO-EACTOR ANOVA. FOR MALE AND FEMALE STUDENTS

\begin{tabular}{|llcccc|}
\hline SourCE & DE & Sum-of-Squares Mean Square & E-Test & R \\
M/F (A) & I & .37 & .37 & .01 & .9333 \\
$\begin{array}{l}\text { Subj/within } \\
\text { groups }\end{array}$ & 90 & 4714.90 & 52.39 & & \\
$\begin{array}{l}\text { Repeated } \\
\text { Measure (B) }\end{array}$ & 5 & 2784.15 & 556.83 & 9.85 & $.0001^{\star}$ \\
AE & 5 & 43.05 & 8.61 & .15 & .9793 \\
$\begin{array}{l}\text { B x Subj. } \\
\text { w. Groups }\end{array}$ & 450 & 25441.47 & 56.54 & & \\
\hline
\end{tabular}

* Indicates Significance at $p<.05$

age

The sub-groups of students 17 and younger and 18 and older were compared to see if the relationship of learning style and age is significant. The mean scores for the entire student population, as listed in Table II, indicated that kinesthetic learning was on the cusp of a major learning style with an average score of $37.6 I$. 
Table VII, however, reveals that after dividing the student population into age groups, kinesthetic learning clearly emerged as a major learning style for students 13 to 17 (38.97), while the students 18 to 22 identified it as a minor learning style with a score of 36.85 . As with the entire student population, the scores for the remaining five learning styles fell within the category of minor learning styles, with no emergent major learning styles.

TABLE VII

MEAN PREFERENCE SCORES FOR TWO AGE GROUPS

Repeated Measures

Ages 13-17

$\begin{array}{llllll}V & \text { A } & K & T & G & I \\ \mathrm{n}=33 & 33 & 33 & 33 & 33 & 33 \\ \mathrm{x}=33.58 & 33.52 & 38.97 & 36.18 & 31.15 & 0.97\end{array}$

std. Dev.

6.78

6.127 .09

6.77

7.95

9.53

Ages 18-22

$$
\begin{array}{llllll}
\mathrm{n}=59 & 59 & 59 & 59 & 59 & 59 \\
\mathrm{x}=37.15 & 35.90 & 36.85 & 34 & 30 & 34.47
\end{array}
$$

std. Dev.

$$
5.93
$$

4.90

7.03

7.25

8.69

9.21

Totals:

$$
\begin{array}{llllll}
n=92 & 92 & 92 & 92 & 92 & 92 \\
\mathrm{x}=35.87 & 35.04 & 37.61 & 34.78 & 30.41 & 33.22
\end{array}
$$


Results of the Anova, shown in Table VIII, indicate a significant difference $(p<.001)$ in mean scores for the six learning styles. There was also a significant interaction effect for age and learning style $(p<.05)$. While the two-factor Anova indicated that there was a significant difference for age interaction and preferred learning styles, it did not indicate which of the six learning styles were significant.

TABLE VIII

TWO-FACTOR ANOVA FOR AGE GROUPS

$\begin{array}{lcccccc}\text { SourCE } & \text { DF } & \text { Sum-of-Squares } & \text { Mean_Square } & \text { E-Test } & \text { E } \\ \text { Age Cat. } & 1 & 56.7 & 56.7 & 1.1 & .2981 \\ \begin{array}{l}\text { Subjects } \\ \text { W/Groups }\end{array} & 90 & 4658.57 & 51.76 & & \\ \begin{array}{l}\text { Repeated } \\ \text { Measure (B) }\end{array} & 5 & 2784.15 & 556.83 & 10.16 & .0001 \text { * } \\ \text { AB } & 5 & 818.34 & 163.67 & 2.99 & .0116 * \\ \begin{array}{l}\text { B x Subj. } \\ \text { W/Groups }\end{array} & 450 & 24666.18 & 54.81 & & \\ \end{array}$

* Indicates significance at $p<.05$ level

To determine which of the six preferred learning styles were significant, the two-factor Anova was followed by six separate one-factor Anovas for age and learning style. A comparison of the two student age groups 
indicated a significant difference occurring for the visual ( $p<.01$ ) and auditory ( $p<.05$ ) styles (see Table IX). With average scores of 37.15 in visual and 35.90 in auditory the young adults reported preferring those two styles significantly more than the adolescents, whose average scores for the same learning styles were 33.58 (visual) and 33.52 (auditory). 
TABLE IX

SINGLE-FACTOR ANOVA FOR TWO AGE GROUPS

VISUAL $\quad \mathrm{N}=92$

Source $\frac{\text { Sum-ef-Squares }}{270.75} \frac{D E}{1} \frac{\text { Meansquare }}{270.75} \frac{E-R a t i o}{6.94} \frac{R}{.0099 *}$ $\begin{array}{llll}\text { error } & 3511.69 & 90 & 39.02\end{array}$

AUDITORY $\quad \mathrm{N}=92$

Source sum-of-squares DE Mean square E-Ratio $R$ $\begin{array}{lccccc}\text { students } & 120.19 & 1 & 120.19 & 4.17 & .0441 * \\ \text { error } & 2595.63 & 90 & 28.84 & & \end{array}$

KINESTHETIC $\quad \mathrm{N}=92$

Source Sum-of-squares $\frac{D F}{95.32}$ Mean square E-Ratio $\frac{E}{95.32}$

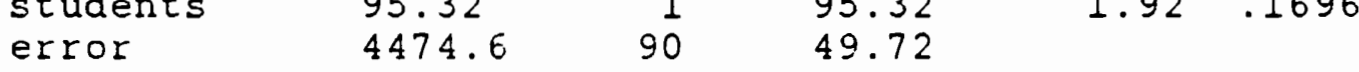

TACTILE $\quad \mathrm{N}=92$

Source Sum-of-squares $D E$ Mean square E-Ratie $P$ $\begin{array}{llllll}\text { students } & 100.74 & 1 & 100.74 & 2.01 & .1599 \\ \text { error } & 4514.91 & 90 & 50.17 & & \end{array}$

GROUP $\quad \mathrm{N}=92$

Source Sum-of-squares DE Mean square E-Ratio $\mathrm{P}$ $\begin{array}{llrlrl}\text { students } & 28.06 & 1 & 28.06 & .39 & .5315 \\ \text { error } & 6400.24 & 90 & 71.11 & & \end{array}$

INDIVIDUAL $\quad \mathrm{N}=92$

Source Sum-of-squares DE Mean square E-Ratio E $\begin{array}{llllll}\text { students } & 259.97 & 1 & 259.97 & 2.99 & .0873\end{array}$ $\begin{array}{llll}\text { error } & 7827.68 & 90 & 86.97\end{array}$

* Indicates significance at $p<.05$ level 
CHAPTER IV

\section{DISCUSSION AND CONCLUSION}

DISCUSSION

This chapter addresses each of the hypotheses in this study. This culture specific study attempted to identify the preferred learning styles of two groups of subjects:

1) Greek students of English as a foreign language

2) Greek teachers of English as a foreign language An assumption had been made earlier that by identifying learning style preferences based on the cultural background of the students, Nunan's (1988) call for involving students in curriculum development would be easier to accomplish. The researcher included teachers in this study in an attempt to address the issue raised by Reid (1987) of how to match student and teacher learning styles.

In order to better address the needs of ESL students in the U.S., Reid developed the PLSPQ to identify which of six learning styles students preferred. In recognition of the shift from a teacher-centered to a student-centered teaching paradigm (Raimes, 1983), as well as to test the hypotheses of this study, the researcher found it 
necessary to categorize half of the six learning styles as teacher-centered, and the other half as studert-centered. The researcher based her categorization of learning styles on descriptions of learning styles and teaching methods characteristic of the student-centered approach (Asher, 1977; Dulay \& Burt, 1985; Enright \& MCCloskey, 1985; Long \& Porter, 1985) and those representative of a teachercentered approach (Oxford, 1990; Quinn, 1984; Rubin \& Wenden, 1987).

After comparing definitions of teacher-centered and student-centered approaches to the descriptions that subjects responded to on the survey, the researcher classified the following three learning styles as teacher centered: I) visual, 2) auditory and 3) individual. Likewise, she categorized the remaining three learning styles as student-centered: 1) kinesthetic, 2) tactile and 3) group. It could be argued that some of the activities that comprised the styles could be described as both teacher-centered and student-centered, but for lack of a more accurate measure, the researcher found it necessary to divide the six styles into two groups under the classifications teacher-centered and student-centered. 
Hi: Greek EEI students report that they orefer

teacher-centered learning styles.

In comparing the students' preferences for teachercentered styles with their preferences for student. centered styles, there was à trend toward teacher-centered learning styles. However, no significant difference was Eound between their scores for teacher-centered and student-centered learning styles $(p) .05)$, therefore the Eirst hypothesis was not supported. Nevertheless, students' Iiking for student-centered learning styles was strong enough that they could be expected to acquire language successfuliy using both styles.

Separating the learning style preferences into two categories, teacher-centered and student-centered, mãy have inadvertentiy exposed the inaccuracy that sometimes comes with labeling. Kinesthetic learning, which is characterized by learning through movement and experimentation, is considered student-centered according to the TESOL profession (Asher, 1977; Legutke, 1991). In the U.S., however, a science class is typically thought of as teacher-centered, even though students conduct lab experiments, which involve kinesthetic behaviors. Likewise, even though teachers and researchers label the low anxiety inducing format of comprehensible input (Terrel1. 1983) as student-centered, comprehension checks, in which the teacher elicits short responses in a 
dictatorial fashion (Fino, 1989), are auditory, a learning style associated with the teacher-centered approach.

Where do we draw the line between definitions of studentcentered and teacher-centered learning styles and teaching methods?

It was as a result of this fine line between teachercentered and student-centered behaviors that the researcher defined learner-centered not as a synonym for student-centered, but as an attempt to address how the student learns best, which may combine both teachercentered and student-centered learning strategies.

The lack of support for the firt hypothesis may further be addressed in terms of motivation to learn. Harmer (1983) contends that advanced ESL/EFL students tend to be more highly motivated to learn than beginning students, as reflected in the number of years they have pursued their study of English. Elaborating on motivational factors, Oxford and Nyikos (1989) maintain that in addition to being more highly motivated to learn, students who have studied ESL/EFL longer than five years tend to make use of a broader range of language learning strategies. The students included in the current study had devoted eight years on average to English language study (see Raw Data, Appendix H). An indication of preference for both student-centered and teacher-centered 
learning styles would have decreased the statistical level of significance $(p<.05)$.

A final contributing factor to the support of the null hypothesis may relate to the varying ages of the students who participated, and how they may have been affected by decisions made by the Greek Ministry of Education. However, this will be addressed more fully in the section on student subgroups (see page 78 ).

H2: Greek EEL teachers report that they prefer

student-centered learning styles.

In comparing the teachers' preferences for teachercentered learning styles to their preferences for studentcentered learning styles, there was a trend for teachers to prefer student-centered learning styles, although they also scored high in teacher-centered learning styles. As with the previous test conducted of the students' learning style preferences, the findings did not support the second hypothesis.

An assumption had been made earlier that the Greek EFL teachers would report a preference for studentcentered methods because of their desire to conform with the Greek Ministry of Education's mandatory studentcentered language learning curriculum. Triandis, Vassiliou and Nassiakou (1968) maintain that while Greeks 
tend to avoid involvemert with authority figures, in situations where there is a perceived possibility of negative or positive reinforcement they may act subserviently toward the authority figure.

Grimm (1990) reports that in Greece, teachers in the private sector, which was the case with the Papaeliou teachers, hold less revered positions than those in the public sector. A frontisterion teacher who indicated a preference for student-centered learning styles would probably have a bette: chance of gaining employment in the public sector than one who reported a preference for teacher-centered learning styles on the basis that the official philosophy on methods for state supported schools is student-centered. Therefore, in terms of job advancement, it would be in the best interests of frontisteria teachers to report preferring learning styles that are in accordance with teaching methods prescribed by the Ministry of Education.

The simultaneously high scores for teacher-centered learning styles may be related to the assumption that the majority of teachers would have learned Englizh using teacher-centered activities. This is frovided they had studied English in Greece, since the commuricative approach was not made the official language learning approach until 1985. Although the teachers reported 
preferring student-centered methods zightly more than the students, further information would be needed to determine whether or not their teacher training had any influence on their responses, and whether or not they teach in the way they prefer to learn.

H3: Greek EFI teachers report that their students prefer student-centered learning styles.

The teachers at the Papaeliou school of English declined to respond to a second questionnaire based on how they felt their students preferred to learn. Since the cover letter which introduced participants to the study (see appendix A) specifically stated that subjects were free to withdraw from the study at any time, the researcher did not pursue the issue, as such coercive attempts might have been interpreted as a violation of the contract between the researcher and participants.

The author was granted permission to conduct her research at the Papaeliou school because she was a member of the director of study's "ingroup". Triandis and Vassiliou (1972) describe the ingroup as "a set of people with whom a person believes it is appropriate to cooperate in order to achieve a particular goal" ( $p$. 140). They describe the ingroup in Greek society as family, friends, the friends of friends and people who show concern. The director of studies at the school agreed to do the study 
out of horor for a mutual friend, who requested that she allow the researcher to lise the papaeliou school as the research site.

To the teachers who participated in the survey, however, the researcher may be an outgroup member. characteristic behavior toward the outgroup member is hostility and suspicion, formulated through a long history of wars, political turmoil and economic unrest (Triandis et al, 1968). Triandis et al. list extreme competitiveness as a Greek national character. A teacher who reported that his/her students preferred methods not endorsed by the Ministry of Education could be called into question by his/her superiors. The subjects were assured confidentiality to all but the researcher, but at least one teacher, who identified himself only by gender, questioned the assurance of confidentiality by signing his name as "anonymity" with a question mark next to it. Though the author's objectives were stated to the subjects, they may have doubted the researcher's veracity on the basis that she was an outgroup member with career interests similar to their own. 


\section{H4: There is a significant difference between the preferred learning styles of Greek EEL students and creek EFI teachers.}

The mean scores for teachers indicated that visual, kinesthetic and tactile were major learning styles, supporting Reid's findings of how non-native speakers of English prefer to learn. The students in this study identified kinesthetic learning as their one major preferred learning style. Statistical analysis revealed that teachers scored significantly higher than students in kinesthetic $(T-42.55, S-37.61)$ and tactile $(T-41.27, S-$ 34.78 ) learning styles, thus partially supporting Hypothesis 4 .

The PLSPQ scores were examined to indicate the following: 1) level of statistical significance $(p<.05)$, and 2 ) negligible, minor or major learning style. In comparing the two groups of teachers and students, one needs to be cautious in interpreting the relevance of the two aforementioned areas in terms of how students and teachers prefer to learn. Labeling a learning style as major, minor or negligible eases the task of identifying individual preferences but does not adequately address how preferences may differ between groups.

Both students and teachers identified kinesthetic learning as a major learning style, yet teachers (42.55) 
reported the style as a preference at a significantiy higher rate than students $(37.6 i)$. One car account for this significance in terms of the subjects' responses to the five-point likert scale. Teachers may have reported that they strongly agreed with types of kiresthetic learning that students simply agreed with. Therefore, although both groups showed a strong preference for kinesthetic learning, it was reported as a particular favorite of the teachers.

Although visual learning was not statistically significant, teachers zeported it as a major learning style with a mean score of 38.00 , while students reported it as a minor learning style with a mean score of 35.87 . Despite the closeness in numbers of the teachers' and students' average scores, their preferences for visual learning were categorized differently. By relying on the labels "major" and "minor" one could assume there was a vast difference between the students' and teachers' preferences for visual learning. By contrast, the results revealed that teachers and students were comparatively close in their responses.

As exempified in this discussion of Hypothesis 4 , labels mean virtually ittle when comparing differences between groups if the numbers involved are ignored. Similarly, while statistical significance contributes to 
the reliability of the findings, the relevance of that significance depends on how the interpreter wishes to make use of the data.

H5: There is a significant difference between the preferred learning styles of male and female Greek EFI students.

No significant differences emerged on the basis of gender. Surprisingly, the average scores of males and females for all six learning styles practically mirrored each other. Another study of Greek students in an academic setting examined the differences between male and female students (Seddon et al, 1990), but like the current study it revealed no significant differences.

Alexis Dimaras (1983) claims the Greek education system has become extremely centralized and that the Ministry of Education has treated all schools alike, leading to uniformity. He also maintains that the tendency toward selectivity through the requirement of university entrance exams drastically narrows the opportunities for many students who dream of going on to higher education. Greek students learn from an early age that to succeed in the education system they need to strictly abide by the rules set by the system. The rigidity of the system does not spell out individual differences whether they be based on personality, gender, 
socioeconomic background, or age. Thus the failure to find a significant difference on the basis of gender may reflect the structure of the Greek education system that festers conformity and homogeneity, not the individuality of either its students or teachers.

Another reason for the lack of significance between genders could relate to their major field of study. Previous ESL/EFL research has represented students from varying ethnic backgrounds and fields of interest (Bassano, 1983; Katz, 1988; Little \& Sanders, 1990; Reid, 1987). Chapter II confirmed that all students in the current study were enrolled in preparatory courses for the proficiency exam. Students representing both genders consistently listed English language study as a major field of interest, contributing to the homogeneity of the group.

Hansen and Stansfield (1982) suggest a link between cognitive style and field of interest. Keefe (1979) classifies perceptual learning styles as cognitive learning styles. Taking this into consideration, one can see how the students' similar fields of interest could have outweighed the effects of their gender roles. This may further explain why no significance was found on the basis of gender. 
HE: There is a significant difference betweer.

the preferred learning styles of Greek EDI

students 13-17 and creet EFI students 18-22

Significant differences emerged for two of the six preferred learning styles: visual and auditory. Therefore, Hypothesis 6 was partially supported. The results of comparative tests between older and younger students reveal that older students prefer teachercentered learning, as apparent in the significant differences occurring in the visual and auditory styles. There was a trend for older students to prefer individual learning, though not significantly.

Another finding of the study was that the students 18 to 22 reported no major or negligible preferred learning styles, unlike the younger students and the teachers, who reported major learning styles, but no negligible learning styles. Despite the older students' reporting of only minor learning styles, kinesthetic emerged as a major learning style after combining the scores for both groups. To account for this occurrence, the younger students' mean score for kinesthetic learning (38.97) was added to the older students' mean score of 36.85. Although there were significant differences in how the older and younger students rated the visual and auditory learning styles, the scores were well within the range of the minor learning style category. Therefore, when the average 
scores of both groups were combined they continued to emerge as minoz leaming styles.

The researcher found a gap in the literature addressing differences in how adolescents and young adults learn. The researcher will attempt to account for the findings on age by looking at the recent history of the Greek education system.

As stated in the revicw of interature, the Greek Ministry of Education has the final say in all curricular decisions. It was further stated that in 1985, the Ministry of Education adopted the communicative approach as the official approach for foreign language instruction. At the time of this revision, the 13-17 year-old participants in the clirrent study averaged in age from six to ten, the age at which students in Greece are first exposed to foreign language learning. The 18 to 22 yearolds would have ranged in age from eleven to 15; therefore they would have already been exposed to the teache:centered approaches that had been the previous official approach for foreign language instruction. Their prior experience with teacher-centered approaches may have preconditioned them to prefer teacher-centered learning styles.

Horwitz (1985) Claims that "students" previous experiences influence their opinions of language learning 
methods" (p. 336) and that they tend to favor the methods that they are the most familiar with. According to Horwitz (1985) the early exposure of students in the older age group to teacher-centered methods may have resulted in their having preconceived notions that teacher-centered methods are superior. Likewise, the younger age group may have preconceived notions that student-centered methods are more effective than teacher-centered methods.

\section{PEDAGOGICAL IMPLICATIONS AND SUGGESTIONS}

The purpose of this thesis was to identify how Greek EFL students and Greek EFL teachers prefer to learn English, with implications for possible curriculum development. Friedman and Alley (1984) and Dunn (1979) point out that many teachers subconsciously assume that the way they learn best is the most effective way for everyone to learn. Based on this information, a teacher who attempts to design a curriculum based on the needs of his/her students, needs to be aware that unconscious biases may interfere with efforts to meet the students' individual needs.

The researcher had several objectives for including both Greek EFL students and Greek EFL teachers in the study. First, measuring the learning style preferences of Greek EFL students would enable a teacher of that student 
population to better address their learning needs. second, one could make generalizations from this study about how Greek EFL students prefer to learn. The inclusion of Greek EFL teachers allowed for a comparison between students' and teachers' learning style preferences. Studies have shown that the matching of student and teacher learning styles can positively affect the students' motivation to learn (Dunn \& Dunn, 1979; Hansen \& Stansfield, 1982). The above objectives have implications for the design of a curriculum centered on the learning preferences of Greek EFL students, by determining what their preferences are, as well as the extent to which those preferences differ from their teachers. The Greek Ministry of Education may find such information beneficial to its own curricular decisions. In the examination of preferred learning styles reported among Greek EFL students and teachers in Greece, several recommendations are suggested. In the assessment of Greek EFL students' and teachers' preferred learning styles, researchers and teachers should not rely on only Reid's instrument, but should consider combining the instrument with interviews and classroom observations. Earlier it was noted that Greeks may use some form of deceit with outgroup members if doing so is seen to benefit ingroup members (Masur, 1985; Triandis et al, 
1968). If the students in the current study had self reported inaccurately, the additional measures of classroom observations and interviews could be compared to the data collected from the self report questionnaires as a further test of the reliability and validity of Reid's instrument.

The researcher stated that she was a member of the U.S. culture. The cultural background of students and teachers may affect their receptiveness to particular teaching methods. A stated purpose of this study was to familiarize Greeks and non-Greeks alike with factors pertinent to learning style preference. One of the factors discussed was the heavy centralization of the Greek education system (Dimaras, 1983; Kazamias, 1990; Panourgia, 1990). Teachers from the West should anticipate that at least some of the methods they value as innovative would conflict with the authoritarian nature of the Greek education system. A learner-centered curriculum in Greece may allow for some student-centered activities, but total immersion in student-centered activities might lead to chaos without the structure and control associated with teacher-centered methods. For example, the use of group projects can be successful in Greece if group members are given individual assignments. This would 
provide a balance by allowing students to work both as individuals and as group members.

Although tactile and kinesthetic learning styles were categorized as student-centered in the current study, such activities can be equally successful in a teacher-centered format. Through her own experience teaching in Greece, the researcher has found that Greek students are quite receptive to "show and tell" type activities and competitive English language games as long as the teacher never relinquishes his/her role as an authority figure.

\section{LIMITATIONS}

This study was limited in terms of its generalizability to Greek EFL students and Greek EFL teachers at frontisteria who had not participated in the current study. The following four factors contributed to the limitations of this study:

1) the researcher's absence from the survey site

2) the sample size

3) the type of school from which the sample was drawn

4) the instrument used.

First of all, the researcher was not present at the survey site, rather the survey was conducted via the postal service and telecommunications. The researcher's absence prevented her from being able to ensure that the 
results of the study were not biased either by the influence of the administrators of the questionniare, or by the collaboration of participants on certain responses. The researcher's absence also prevented her from being able to explain portions of the survey that participants and administrators of the questionnaire may have questioned. It was discussed earlier in this chapter that the teachers at the Papaeliou school may have considered the researcher a member of their outgroup. The presence of the researcher at the site may have allowed the researcher to build a trust with the teachers, which could have prevented them from withdrawing from the second survey in which they were asked to report on their students' learning style preferences.

A second limitation of the study relates to sample size. Though a sample of 92 students carries moderate external validity, the breakdown of students into subgroups carries lower external validity by virtue of the smaller number of students in each subgroup. The small sample of eleven teachers carries little external validity. The teacher sample, as well as the student sample, could both have been expanded by including other schools in the study. 
A further limitation of the sample relates to the type of school from which teachers and students were drawn. Though Greek students commonly study foreign languages in private schools known as frontisteria, these schools are not required to follow the same uniform curriculum as the state supported schools. Thus, these schools exercise more freedom in the methods they use to teach. Furthermore, frontisteria teachers are not required to have a college degree, though they are required to have a certificate of proficiency in the target language. In regard to limitations related to the students who attend the frontisteria, these students tended to represent a homogenous group of students, representing primarily middle and upper class. Due to the numbers of hours per week that frontisterion students devote to language study, they also may have experienced a variety of instructional methods that students in the state schools would not have had the opportunity to experience.

The fourth limitation is the survey instrument itself, a self report questionnaire. The validity of a self report questionnaire relies on the honesty of the respondents (Babbie, 1992). Subjects may indicate a preference for a learning style that differs from their own on the basis that they believe it to be superior for 
language achievement. This may be particularly true of teachei subjects who have beer irstructed on the merits of a particular learning etyle in terms of what styles result in greater language learning. They may believe that certain learning styles are more effective in facilitating language acquisition, but do not actually prefer learning or teaching in those styles. One also needs to question the effect of culture on the use of self report. Masur (1985) states that in Greek culture, lying is acceptable when it is used to protect the privacy and best interests of the individual's family. The statement she makes could be inclusive of the ingroup, of which the family is an integral unit. How students and teachers responded may have been influenced by how they believed their parents, peers or the school administration would want them to respond.

Another limitation of the survey involves the adaptability of the PLSPQ to Greek culture. Reid's descriptions of learning activities are often vague and limited in the range possible for each of the six learning styles. For example, all statements pertaining to the visual learning style involve the reading of printed material. The use of pictures to reinforce a concept also relies on visual perception yet this was excluded from the questionnaire. The translation of Reid's instrument into 
Greek may not have been enough to ensure an accurate measure of the subjects' preferred learning styles. The researcher could have increased the internal validity of the survey by adapting it to Greek educators' categorizations of the six perceptual learning styles.

\section{CONSIDERATIONS FOR FUTURE RESEARCH}

Future research related to the learning style preferences of Greek EFL students and Greek EFL teachers should address the following: conducting a iongitudinal study, expanding the data collected, norming the instrument so that it is more appropriate for Greek culture, and acquiring additiona! information on how Greek EFL students and Greek EFL teachers prefer to learn through the use of classroom observations and interviews with students and teachers.

I would recommend that future research on the learning style preferences of Greeks be longitudinal. Keefe (1979) explains that a learning style remains for the most part unchanged. It would be interesting to measure the preferences of the participants in the current study after a period of six months or a year. Comparing the responses would help determine whether preferences indicated were actual learning styles. According to Keefe (1979) the two questionnaires would have to be identical 
in order to indicate a learning style.

The data collected for the current study included occupation (student or teacher), gender, and age. Future research could include foreign teachers in the teacher sample to see tow their reported learning style preferences compare to the learning style preferences of Greek EFI students and Greek EFL teachers. Because of the stated differences between the schools known as frontisteria and the state run schools, a study sample that represented both types of schools would be required to accurately measure the learning style preferences of Greek EFL teachers and Greek EFL students. Not only would such a study be higher in external validity than the present study, but it would also allow for comparisons to be made between the two types of schools.

As for the instrument, the fact that the current replication of Reid's questionnaire, as well as replications by Pia (1989) and Hoffner (1991), reported no negiigible learning styles, raises the question of the reliability and validity of the questionnaire. For example, it could be that Chinese, Greek, and Japanese students prefer all learning styles, but the diversity among these cultures suggests a closer look at the usefulness of Reid's instrument in culture specific studies. Some cultures may be more inclined than others 
to respond neutrally in order to maintain the status quo. Whether or not this was the case with the current study, as well as studies by Pia and Hoffner needs Eurther investigation.

A variation of the questionnaile, such as one with a six or four point scale, might reveal more reilible results by omitting a neutral response. In a stuay of self disclosure in Japan, Sugita (1992) switched from a seven point likert type scale to a six point scale which successfully eliminated the clustering of responses around the neutral midpoint.

As stated earlier, there exists a fine line between activities that are considered teacher-centered and student-centered. Future researchers might address ways to identify learning styles on a continuum. The elimination of discrete categories would reduce the often vague descriptions that Reid provides for each of the six perceptual learning styles.

Even with a questionnaire specifically rormed to the Greek population, without the use of classroom observations or interviews with students and teachers it would be difficuit for the researcher to make any definite statements as to Greek students' and Greek teachers' learning style preference. Aithough Greek teachers' definitions of teacher-centered and student-centered 
approaches (Dandoulakis, 1986; Papaeliou, 1992) are comparable to U.S. definitions of the terms ifraines, 1983), without observing the approaches in person one can not lnow to what extent the two cultures differ in terms of classroom activities.

\section{CONCLUSION}

The following summarizes the findings of this study in terms of the hypotheses tested. In response to Hypotheses 1 and 2 , there was a trend for Greek EFL students to prefer teacher-centered learning styles, while there was a trend for Greek. EFL teachers to prefer student-centered learning styles. Despite these trends, the findings failed to support the first two hypotheses. No data were available to test Hypothesis 3 . As for Hypothesis 4, the Greek EFI teachers reported preferring kinesthetic learning and tactile learning aignificantly more than the Greek EFL students. Though these were oriy two of six learning styles, they partially supported the presumed difference between the preferred learning styles of Greek EFL teachers and Greek EFL students. In response to Hypothesis 5, no significant difference was reported in the learning style preferences of male or female Greek EFL students. Is for Hypothesis 6 , the researcher found that Greek EFL students 18 to 22 , preferred two of the $E x$ 
learning styles, visual and auditory, significantly more than the Greek EFL students 13 to 17 , fartially supporting the hypothesis that Greek EFI students 13 to 17 and Greek. EFL students 18 to 22 would differ in preferred learning styles. Given this information, two of the six hypotheses were at least partially supported by the results of the questionnaire.

The literature review addressed the need for cultural awareness on the part of teachers who go abroad to teach if they are to adequately serve the needs of the students in the host country (Hofstede, 1986; Prodromou, 1992). This thesis addressed that need for cultural awareness in part, by providing information on how Greek studerts and teachers prefer to learn English as well as by including a brief review of the role of the Greek Ministry of education in the area of foreign language teaching.

The Greek education system has been identified as authoritarian in nature (Grimm, 1990; Panourgia, 1990). This is aligned with the general belief that Greek organizations are authoritarian based (Dimaras, 1983; Hofstede, 1980; Masur, 1985; Triandis \& Vassiliou, 1972). However, the edicational research on Greece fails to take this authoritarian variable into account (Eritish council, 1986; Dandoulakis, 1986). How do Greeks deal with democratic student-centered activities when many of the 
organizations they come in contact with, including their own families, are very authoritarian and paternalistic? Perhaps the discussion of what methods are more effective should not be looked at in terms of what methods have been proven effective in the U.S. or the U.K., but tow receptive they will be in the conteyt of Greek culture.

In order to discuss the contradictory nature of student-centered teaching in the context of Greece, the researcher refers to Triandis et al. (1968) who discussed authority in terms of the ingroup and the outgroup. Although authoritarian ingroup members, persons with special skills or knowledge, are respected by ingroup members, authoritarian outgroup members generally are ignored. One wonders at the implications of this in the classroom, where surely ingroups and outgroups exist.

student-centered teaching requires students to spend class time collaboratively working in small groups or ir pairs. In the context of the Greek classroom, a group with a combination of an outgroup authority figure and ingroup members could face the following complications. The outgroup member, because of his/her authority position, may feel that his/her ideas are the correct ones. Because the ingroup members ignore the outgroup member, whom they view with suspicion and hostility, the group fails to effectively accomp?ish its task. In such a 
situation, it would seem that teacher-centered methods would create less Eriction because the teacher wouldn't have to worry about the implications of certain group combinations. This would be particularly pronounced in the state-run schools, where there are often more than 50 students in a single classroom.

In contrast with the state schools, the frontisteria, tend to have fewer thar 20 to 25 students in the class, making it much easier for teachers to get acquainted with and recognize the needs of their students. In addition. frontisteria serve a smaller population of students than the state-run schools and tend to be attended by students living within the vicinity of the schools, increasing the opportunity that students already know one another or are members of each other's ingroups. Even in the case where this is not so, the smaller numbers per class make it easier for the teacher to facilitate language learning either by avoiding ingroup/outgroup mixes or by settling conflicts that may arise based on such mixes.

The EFL teacher who goes to Greece may find it of interest that Greek students reported kinesthetic learning as a major preferred learning style, and tended to prefer teacher-centered learning styles slightly more than student-centered learning styles. The author, however, cautions EFL teachers who may work in the public sector 
that EFL teachers in Greece are not allowed to make any curricular changes without pricr approval from the Greek Ministry of Education. Greek teachers have unsuccessfully fought for educational reforms during the 150 years since the Greef education system was centralized under the Grebl Ministry of Education and Religion (Kostakis, 198?; Panourgia, ig9o). Greeks have had to struggle against traditional values of paternalism and authoritarianism. established during the Byzantine era, reinforced during ottoman occupation and maintained through the omnipresence of the Greek orthodox church, which is inseparable from Greek society (Dimaras, 1983; Kazamias, 1990; and Triandis, 1968).

In contrast to the state run schools the frontisteria allow their teachers a little more decisive freedom in terms of teaching methodology and curriculum development. Frontisteria teachers are not legally required to abide by the Ministry of education's strict guidelines. Because of trie rigid requirements for foreign teachers employed in the public sector, most foreign teachers in Greece find employment in the frontisteria. They would therefore be allowed a littie more freedom in terms of teaching methodology than their counterparts at the state schouis. The endorsement of a student-certered teaching approach in Greece contrasts with an education system that 
is tightly controlled by the Greek Miristry of Education. The collaborative nature of student-centeredness also contrasts with a culture that is characterized as authoritarian, competitive and aggressive (Rroome, 1990; Triandis \& Vassiliou, 1972). The Greek EFL teachers participating in this study reported student-centered learring styles as preferences, aligning with the Greek Ministry of Education's endorsement of a student-centered curriculum. Conflicting with the teachers' preferences, the Greek EFL students, reported a preference toward teacher-centered learning styles. which involve the competitiveness and authoritarianism that mark the Greek character.

Learner-centeredness, as defined by the researcher, acts as a mediating force between the contrasting teachercentered and student-centered methods, by considering what methods students prefer. This study, which was generalizabie to teachers and students at the papaeliou school of English, found the same conflict between teacher-centeredness and student-centeredness that learner-centeredness is expected to reduce. If there is a conflict between the learning style preferences of Greek EFI teachers and Greel: EFI students, as this study suggests, to what extent, if any should teachers impose their owr teaching philosophy on their students? 
From the perspective of Western intellectual thought, conflict is seen as something to avoid. Broome (1990), however, warns that conflict is culture bound. He explains that in Greece, conflict is seen as a ratural course of life that is unavoidable. He offers Triandis et al's (1968) distinction between ingroups and outgroups in Greek society as evidence that Greek culture accepts conflict. In order for a conflict to be resoived a change needs to occur. Hofstede (1980) describes Greece as a country high in uncertainty avoidance, and therefore resistant to change. How influential the results of the current study and related studies will be on curriculum development in Greece, depend on the success of the teachers in Greece who continue to strive for educational reform in a culture that is resistant to it. 


\section{REFERENCES}

Alsop, T.W. (1979). A need to discover how students have been taught. Eoreign Language Annals, 12, 197-100.

Antier, M. (1976). Language teaching as a form of witchcraft. English Language Teaching Journal, 31 , $1-10$.

Archer, C.M. (1986). Culture bump and beyond. In J.M. Valdes (Ed.) culture bound: Bridging the cultural gap in language teaching (pp. 170-177). New York, NY: Cambridge University Press.

Asher, J.J. (1977). Learning another language through actions: The complete teacher's guide. Los Gatos. CA: Sky Oaks Productions.

Babbie, E. (1992). The practice of secial research. Belmont, CA: Wadsworth Publishing Company.

Babich, A.M., Burdine, P., Albright, I., \& Randal, E. (1975). C.I.T.E. learning styles inventory.

Wichita, KS: Murdock Teaching Center.

Bassano, S.K. (1983). Unfamiliar instructional practice and its relationship to student emotional distress in the ESI classroom (Report No. FL013695). Los Angeles, CA: University of California at Santa Cruz. (ERIC Document Reproduction Service No. ED 230 034)

Bourantas, D., Anagnostelis, J., Mantes, Y., \& Kefalas, A. G. (1990). Culture gap in Greek management. organizational studies, 11/12, 261-283.

Bowen, J.D., Madser, H. \& Hilferty, A. (1985). TESOL techniques and procedures. Rowley, MA: Newbury House Publishers, Inc.

Eritish Council (1982). English teaching profile: Greece (Report No. FLo13741). London, England: British Council, English language and literature division. (ERIC Document Reproduction Service No. ED 230 062)

British Council (1986). English teaching prefile: Greece (Report No. FLO16338). London, England: 
British Council, English language and literature division. (ERIC Document Reproduction Service No. ED 277275 )

Broome, B.J. (1990). "Palevome": Foundations of struggle and conflict in Greek interpersonal communication. The southern Communication Journal, 55, 260-275.

Brown, H.D. (1987). Principles of language learning. Englewood Cliffs, NJ: Prentice Hall.

Burt, M.K. \& Dulay, H.C. (1983). Optimal language learning environments. In J.W. Oller, Jr. and P.A. Richard-Amato (Eds.) Methods that work (pp. 38-48). Rowiey, MA: Newbury House.

Campbell, J.K. (1983). Traditional values and continuity in Greek society. In R. Clogg (Ed.) Greece in the l980s (pp. 184-196). New York, NY: St. Martin's Press.

Curtin, J.B. (1979). Attitudes to language learning: The adult student. English Language Teaching Journal, 33, 672-689.

Dandoulakis, G. (1986). Towards a student-centred teaching of English literature (Report No. FLO16083). Brighton, England: Annual meeting of the international association of teachers of English as a foreign language. (ERIC Document Reproduction Service No. ED 274 200)

Dimaras, A. (1983). Europe and the 1980s: A double challenge for Greek education. In R. Clogg (Ed.) Greece in the 1980s. New York, NY: St. Martin's Press.

Doyle, W., \& Futherford, B. (1984). Classroom research on matching learning and teaching styles. Theory Inte Practice, 23, 20-25.

Dunn, R. (1984). Learning style: state of the science. Theory Inte Practice, 23, 10-19.

Dunn, R.S. \& Dunn, K.J. (1979). Learning styles, teaching styles: Should they... Can they... be matched? Educational Leadership, 36, 238-244.

Enright, D.C. \& MCCloskey, M.L. (1985). Yes, talking! 
Organizing the classroom to promote second language acquisition. TESOL Ouarterly, 19, 431-453.

Farquharson, M. \& Stoynoff, S. (1990). Japanese learning preferences: A study of four intensive English programs. The ORTESOL Journal, 11, 75- 83.

Friedman, F. \& Alley, R. (1984). Learning/teaching styles: Applying the principles. Theory Into Eractice, 23, 77-81.

Gardner, R.C. (1978). Attitudes and motivation: Their role in second language acquisition. In J.W. Oller and J.C. Richards (Eds.) Focus on the learner: pragmatic perspectives for the language teacher ( $p p$. 235-245). Rowley, MA: Newbury House.

Grimm, R.E. (1990). Egalitarianism and productivity: Rhetoric and reality in Greek educational reform since the fall of the military junta in 1974. Modern Greek studies Yearbeok, 6, 81-96.

Hansen, J. \& Stansfield, C. (1982). Student-teacher cognitive styles and foreign language achievement: A preliminary study. Modern Language Journal, 66, 26373.

Harmer, J. (1983). The practice of English language teaching. New York, NY: Longman Inc.

Hoffner, E.A. (1991). A study of the perceptual learning style preferences of Japanese students. Unpublished master's thesis, Portland State University.

Hofstede, G. (1980). Culture's consequences: International differences in work-related values. Eeverly Hills, CA: Sage.

Hofstede, G. (1986). Cultural differences in teaching and learning. International Journal of Intercultural Relations, 10, 301-320.

Horwitz, E.K. (1985). Using student beliefs about language learning and teaching in the foreign language methods course. Foreign Language Annals, 18, $333-340$.

Hosenfeld, C. (1979). Cindy: A learner in today's foreign language classroom. In W. Born (Ed.) The 
foreign language learner in today's classroom

environment.

Middlebury, VT: Northeast Conference.

Johnson, J.S. \& Newport, E.L. (1989). Critical period effect in second language learning: The influence of maturational state on the acquisition of English as a second language. Cognitive Psychology, 21, 60-99.

Kaplan, R.E. (1980). Cultural thought patterns in intercultural education. In $K$. Croft (Ed.) Readings en English as a second Language for teachers and teacher trainees. Cambridge, MA: Winthrop.

Katz, R. (1988). An effective teacher - the students' Doint of View (Report No. FLO171815). Chicago, il: Annual meeting of the teachers of English to speakers of other languages. (ERIC Document Reproduction Service NO. ED 304 017)

Keefe, J.W. (1979). Student learning styles: Diagnosing and prescribing programs. Reston, VA: National Association of Secondary school Principals.

Kokkevi, A., Typaldou, M., Repapi, M., Adamou, A., and Stefanis, C. (1981). The MMPI on a Greek population sample of adults and adolescents. Materia Medica Greca, 2, 515-521.

Konstantellou, E. (1990). The myths of modernization: Post-1974 educational reform in Greece. Modern Greek Studies Yearbock, $6,55-80$.

Kostakis, A. (1987). Differences among school outputs and educational production functions. Sociology of Education, 60, 232-241.

Kramarae, C. (1981). Women and men speaking. Rowley, MA: Newbury House.

Krashen, S.D. (1982). Second language acquisition theory. In S.D. Krashen (Ed.) Principles and practices in second language acquisition (pp. 9-56). New York, NY: Pergamon Press.

Krashen, S.D. \& Terrell, T.D. (1983). The natural apdroach. New York NY: Pergamon Press.

Larsen-Freeman, D.L. (1986). Techniques and principles in language teaching. Oxford University Press. 
Legutke, M. \& Thomas, H. (1991). Rrocess and experience in the language classroom. New York, NY: Longman, Inc.

Lindsay, P. (1977). Resistances to learning EFL. English Language Teaching Journal, 31, 184-190.

Little, G.D. \& Sanders, S.L. (1990). Resistance te learning? Student reaction to communicative language teaching (Report No. FLO18499). South Carolina: University of South Carolina. (ERIC Document Reproduction Service No. ED 319 232)

Long, M.H. (1977). Group work in the teaching and learning of English as a foreign language - problems and potential. English Language Teaching Journal, 32. 285-292.

Long, M.H. \& Porter, P.A. (1985). Group work, interlanguage talk and second language acquisition. TESOL Quarterly, 12, 207-227.

Masur, J. (1985). The society and its environment. In R.S. Shinn (Ed.) Greece: A country study. United States Government: Secretary of the Army.

Mckay, S. (1983). Some limitations in teaching composition. In J. Handscombe, R.A. Orem and B.P. Taylor (Eds.) en TESOL '83: The question of control. Washington, DC: TESOL 1984.

Menyuk, P. (1971). The acquisition and development of Language. Englewood Cliffs, $\mathrm{NJ}$ : Prentice Hall.

Nunan, D. (1988). The learner centered curriculum. New York, NY: Cambridge University Press.

Nunan, D. (1991). Communicative tasks and the language curriculum. TESer quarterly, 25, 279-295.

Oxford, R.L. (1990). Language learning strategies. New York, NY: Newbury House Publishers.

Oxford, R. \& Nyikos, M. (1989). Variables affecting choice of language learning strategies by university students. The Modern ianguage Journal, 73, 291-300.

Panourgia, E.K. (1990). On the political and symbolic capital of educational reforms in Greece. Modern 
Greek studies Yearbook, 6, 73-80.

Pia, A. (1989). Rreferred perceptual learning styles of Chinese students. Unpublished master's thesis, Portland state University.

Pino, B.G. (1989). A comprehensible input sequence for ESL. (Report No. FLO18275). San Antonio, TX: Annual Convention of Teachers of English to Speakers of other Languages. (ERIC Document Reproduction Service ED 314333 )

Prodromou, L. (1988). English as cultural action. English Language Teaching Journal, 42, 73-83.

Prodromou, L. (1992). What culture? Which culture? Cross-cultural factors in language learning. English Language Teaching Journal, 46, 39-50.

Quinn, R. (1984). Functional approaches in language pedagogy. Annual Review of Applied Linguistics. Cambridge: Cambridge University Press.

Raimes, A. (1983). Tradition and revolution in ESL teaching. TESol Quarterly, 17, 535-552.

Reid, J. (1987). The learning style preference of ESL students. TESOL Quarterly, 21, 87-111.

Reid, J. (1989). The dirty laundry of ESL survey research. TESOL Quarterly, 23, 323-338.

Reinert, H. (1976). One picture is worth a thousand words? Not necessarily! Medern Language Journal, 60, $160-168$.

Rubin, J. \& Wenden, A. (1987) Learner strategies in language learning. Englewood Cliffs, NJ: Prentice Hall.

Sakka-Paraskeva, S. (1984). Educational psychology research in Greece. Contemporary Educational Esychelegy, 2, 214-228.

Savignon, S.J. (1991). Communicative language teaching: state of the art. TESOL Quarterly, 25, 261-277.

Seddor, G.M. , Papaioannou, V.G. \& Pedrosa, M.A. (1990). A comparison of written and oral methods of testing in science. Research in science and Technological 
Education, \&, 155-162.

Shuter, R. (1990). The centrality of culture. The Southern Communication Journad, 55, 237-249.

Sproull, N.L. (1988). Handboot of research methods: A guide for practitioners and students in social sciences. Metuchen, NJ: The Scarecrow Press.

Stevick, E.W. (1980). l'eaching languages: A way and ways. Rowley, MA: Newbury House Publishers, Inc.

Tarvin, W.L. \& Al-Arishi, A.Y. (1991). Rethinking communicative language teaching: Reflection and the EFL classroom. TESOL quarteriy, 25, 9-27.

Terrel1, T.D. (1983). The natural approach to language teaching: An update. In J.W. Oller, Jr. \& F.A. Richard-Amato (Eds.) Methods that work. Rowley, MA: Newbury House.

Triandis, H. \& Vassiliou, V. (1972). Interpersonal influence and employees selection in two cultures. journal of Applied Psychology, 56, 140-145.

Triandis, H., Vassiliou, V. \& Nassiakou, M. (1968). Three cross-cultural studies of subjective culture. Journal of Personality and Social Psychology Monograph, \&, (4, pt.2).

Van EK, J. \& Alexander, L.G. (1975). The threshold level in a European unit/credit system for modern language learning by adults. Oxford: Pergamon Press.

Wilkin, H.A. (2976). Cognitive styles in learning and teaching. In S. Messick et al. (Eds.) Individuality in Learning. San Francisco, CA: Jossey-Bass, Inc.

Zamel, V. (1985). Responding to student writing. mescl Quarterly, 12, 79-101. 
APPENDIX A

COVER LETTERS 
Dear Teacher,

You are invited to participate in a study that was originally designed by Professor Joy Reid at the

University of Colorado. It will look at how students (and teachers) prefer to learn new information. The purpose of this study is to test existing models for the best way to teach English to students for whom English is a second language. By participating in this study, you will help us to better understand ways in which teachers from Greece prefer to learn new information.

This survey is not intended to evaluate your effectiveness as a teacher in any way; it is intended to show the way you as a learner think you acquire new information best. Please try to respond as truthfully as possible.

As a subject in this study, you will not be anonymous to the researcher, however, your identity will be kept confidential at all times. Data will be coded as group data. In this way, information from this study can be kept on file without violation of confidentiality.

It is hoped you will find the survey results of use to you as a teacher in your EFL classes. If you need to ask the administrator of this questionnaire any questions, please feel free to do so. Also, if you would not like to take part in this study, you are under no obligation to participate. You can also withdraw from the study at any time without jeopardizing your relationship with the research or with your school.

This study is being conducted under the supervision of Dr. Devorah Lieberman. If you experience any problems as a result of your participation in this study, please contact Dr. Lieberman at (503) 725-3534, or the secretary of the Human Subjects Research Review Committee, Office of Grants and Contracts, 345 Cramer Hall, Portland state University, Fortland, Oregon. 
Dear student,

You are invited to participate in a study that wili look at how students prefer to learn new information. The purpose of this study is to help teachers to be more effective in teaching English to Greek students. By answering the following questions, you will help us to better understand ways in which you prefer to learn new information. This survey is not intended to evaluate your teacher in any way, it is intended to show the way you as a learner think you learn best.

While you will not be anonymous to the researcher, your identity will be kept confidential at all times. Data will be coded as group data.

If you need to ask the administrator of this questionnaire any questions, please feel free to do so. Also, if you feel you would not like to take part in this survey, you are under no obligation to participate. You can withdraw from this study at any time without jeopardizing your relationship with your teachers or your school.

This study is being conducted under the supervision of Dr. Devorah Lieberman. If you experience any problems as a result of your participation in this study, please contact Dr. Lieberman at (503) 725-3534, or the secretary of the Human Subjects Research Review committee, Office of Grants and Contracts, 105 Neuberger Hall, Portland state University. 
Dear Parent,

Your child is being asked to participate in a study that will look at how students prefer to learn new information. This survey is not intended to evaluate your child, or your child's teacher in any way. It is intended to help us better understand how your child best learns new information by answering a series of questions.

While your child's identity will not be anonymous to me, his (her) identity will be kept confidential at all times. Answers to the questions will be put together with other answers so that your child's particular answers cannot be identified.

If your child feels he (she) would not like to participate in this survey, he (she) is under no obligation to participate. Your child can withdraw from this study at any time without jeopardizing his (her) relationship with his (her) teachers or with the Papaeliou school.

This study is being conducted under the supervision of Dr. Devorah Lieberman. If your child experiences any problems as a result of his (her) participation in this study, please contact Dr. Lieberman, (503) 725-3534, or the secretary of the Human Subjects Research Review Committee, Office of Grants and Contracts, 105 Neuberger hall, Portland State University, Portland, Oregon. 
APPENDIX B

INFORMED CONSENT FORMS 
INFORMED CONSENT FORM

part in this research project on, agree to take

I understand that the study involves my responding to statements on a self report questionnaire.

Debra Gregory has told me that the purpose of the study is to measure my preferred learning style.

I may not receive any direct benefit from taking part in this study, but the study may help to increase knowledge that may help others in the future.

Debra Gregory, and those acting on her behalf, have offered to answer any questions I have about the study and what I am expected to do.

They have promised that all information I give will be kept confidential and that the names of all people in the study will remain anonymous.

I understand that I do not have to take part in this study and that I may withdraw from it at any time without its affecting my course grade or my relationship with the Papaeliou School of English.

I have read and understand the above information and agree to take part in this study.

Late:

Signature: 
I agree to allow my child

to take part in a research project that involves my child's responding to statements on a self report questionnaire.

Debra Gregory has informed me that the purpose of the study is to measure my child's preferred learning style. My child may not receive any direct benefit from taking part in this study, but the study may help to increase knowledge that may help others in the future.

Debra Gregory, and those acting in her behalf, have offered to answer any questions I may have about the study, and what my child is expected to do.

They have promised that all information my child gives will be kept confidential and that the names of all people in the study will remain anonymous to all but the researcher.

I understand that my child does not have to take part in this study and that he (she) may withdraw from it at any time without its affecting his (her) course grade or his (her) relationship with the Papaeliou School of English.

I have read and understand the above information and agree to allow my child to take part in this study.

Date: 
APPENDIX C

PERCEPTUAL LEARNING STYLE

PREFERENCE QUESTIONNAIRE 
PERCEPTUAL LEANNING STYLE FREFERENCE QUESTIONNAIRE

Demographic Data

NAME $A G E$ DATE

NATIVE COUNTRY NATIVE LANGUAGE

GRADUATE STUDENT UNDERGRADUATE MALE FEMALE

HOW LONG HAVE YOU STUDIED ENGLISH?

WHAT IS YOUR MAJOR FIELD OF STUDY?

DIRECTIONS:

People learn in many different ways. For example, some people learn primarily with their eyes (visual learners) or with their ears (auditory learners); some people prefer to learn by experience and/or by "hands-on" tasks (kinesthetic or tactile learners); some people learn better when they work alone while others prefer to learn in groups. This questionnaire has been designed to help you identify the way(s) you prefer to learn.

The following is an explanation of some of the terms that apply to this questionnaire.

a) In questions 2 and 8 , "doing something" and "doing things" iefers to physical involvement or taking part in a project. Class excursions or drama activities are examples.

b) In question 11, "the model" refers to creatirig something which serves as an example of the information zeceived, zuch as drawing diagrams or graphs.

c) In question 19, the playing of a role refers to the playing of a character with the intention of getting an idea across or learning one central idea.

Read each of the following statements. Please respond to the statements AS MUEY AEPLY TO YOUR STUDY OF ENGLISH. Decide whether you agree or disagree with each statement. For example, if you strongly agree, mark:

\begin{tabular}{|c|c|c|c|c|}
\hline $\begin{array}{l}\text { STRONGLY } \\
\text { AGREE } \\
X\end{array}$ & AGREE & UNDECIDED & DISAGREE & $\begin{array}{l}\text { STRONGLY } \\
\text { DISAGREE }\end{array}$ \\
\hline
\end{tabular}




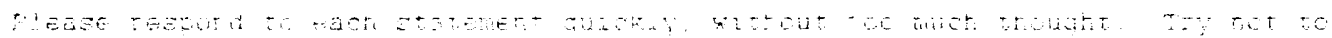

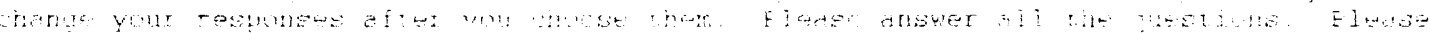

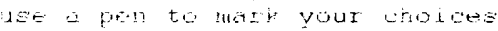

PEROEPTUAL LEAFIING STYLI PLEEERENCE QUFSTIONAATRE

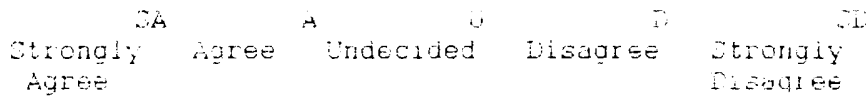

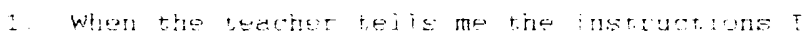
understand bet ter

$\because$ I preier to learr by doing something is ciase.

$\because \quad I$ get more whi dore wher i work w th others

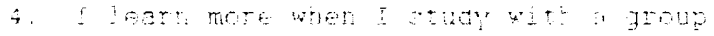

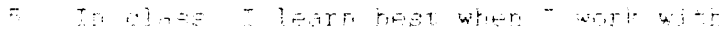
atists

6. I learn better by reading what the teacher wites on the ohalknoard

7 When someone tells me now to do someining in ciass, í Learil it pettei

3. Wher I do things in clase I iecir better.

9. I remember thirgs I have hedrd $1 \mathrm{r}$ ides betrer thar thange i have reac

:0. Wher I read ingtruitions. I remeber tom siptor.

11. I loarn more when 1 can make is model it sometting

i? i inderstara bet,er when $t$ read instructions

3. Wher I Etudy alone, I rememie: bings B.t- 5

14. I learn more wher: I gar rake something for a clase project

15 I enroy Learnind in class by doing experiments

ib. ¿ inorr butier wren I mone drowirge al Istudy.

i. i Learr better a thas when the teadiez yivea $\approx$ andire

Ly wher I wort alone. I lasm better

ig I understurd things better in ilass wher I participate in role-piayina.

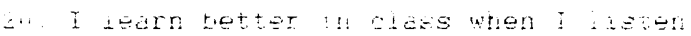
i. $\Rightarrow$ Otifille

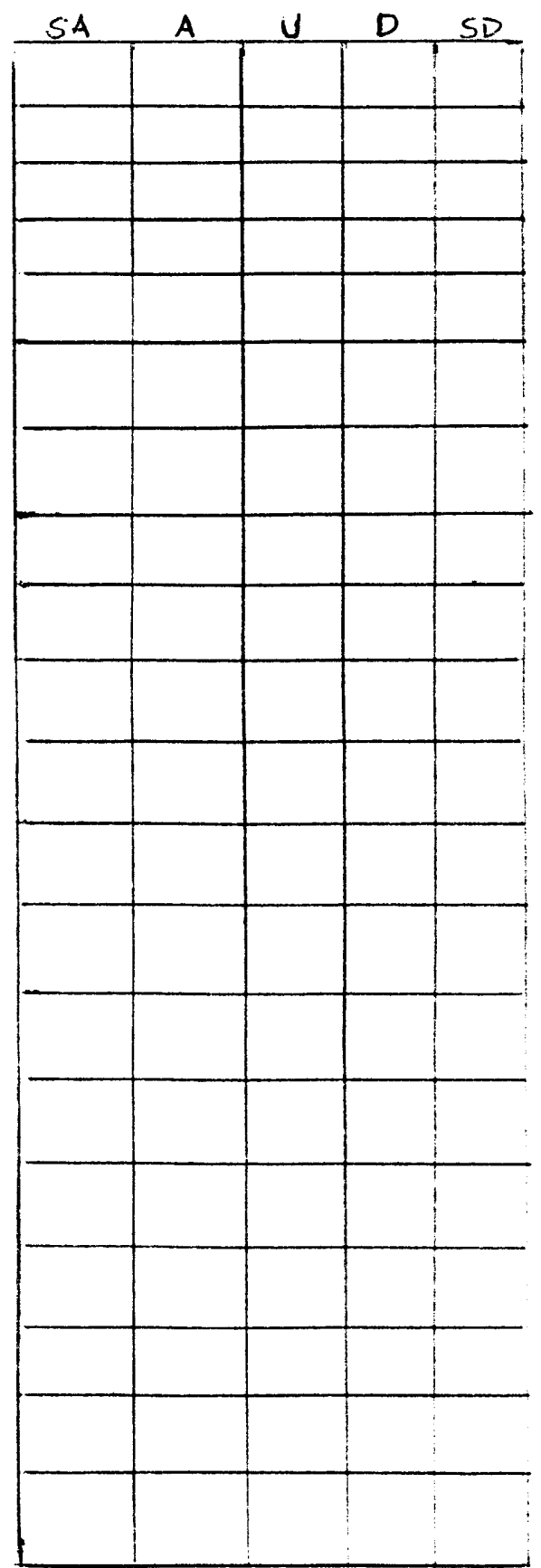


-1. : er: w torking on an sesignment whth t.yo ur three alassmatos

a. When t buld something. I remember what I nave learned bettor.

33. I pleigr wo etuay with others

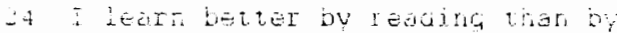
istening to somante

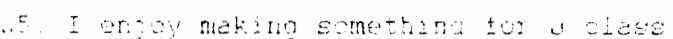
$\therefore-\in=$

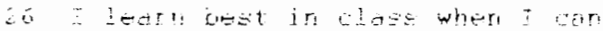

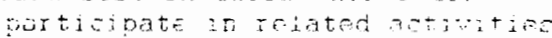

$\because$ In flase I work tot to whon I whrk Aning

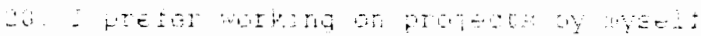

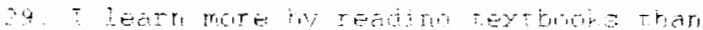
by isetening to loztures

30 I frofor to wow ty nyolf

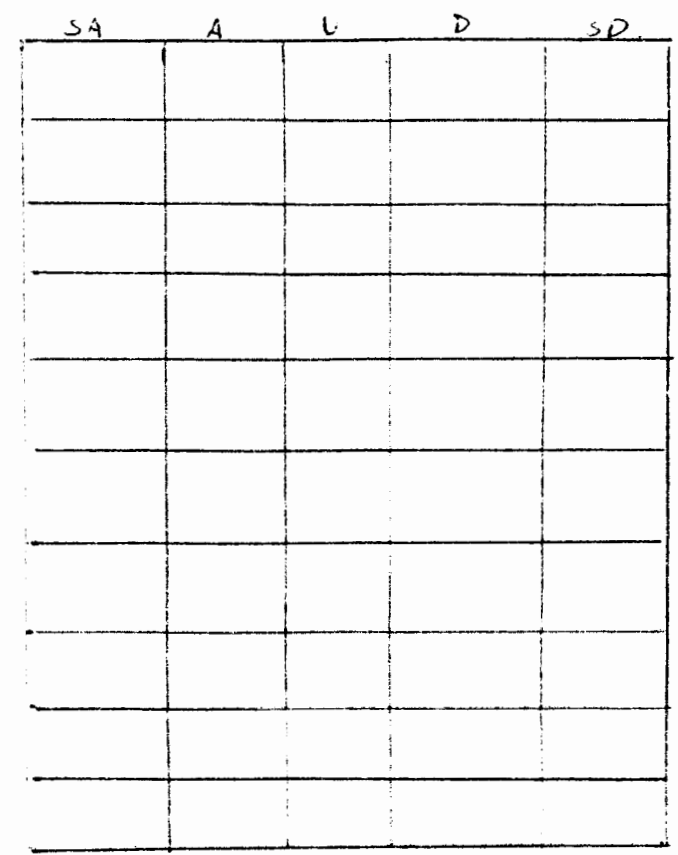


There are s questlons for each ledrning style category in eils questionnalre. The questlons are prouped below accoroting to each leaming siyle. God question you inswer has tlons are arouped

\begin{tabular}{|c|c|c|c|c|}
\hline$s A$ & 1 & $U$ & 0 & $s o$ \\
\hline$s$ & 1 & 3 & 2 & 1 \\
\hline
\end{tabular}

fill In the blanks belox with the nuoerical value of each answer. For example. If you answered Sirongly Agree (SA) for quesstion 6 (a risual question). vrlte a number $S$ (SA) on the blant neat to question 6 below.

- risuel

$$
6.5
$$

Then you have conoleted all the numerical values for Visual, as the numbers. Multiply the answer by 2 . And put the total in the approprlate blant. :

follow this process for each of the learning style categories. Men you are finished. look at ine scale at the botton of the odge: it will helo poo deteraine gour ms jor learning style preference(s). your anor learning style preference(s). and those learning style(s) inst are negligiole.

If you need help. Dlesse ask your teacher.

\section{risuac}

6.

10.

12 .

24.

29.

TOTAL $\times 2 \cdot$ (score)

AUDTTORY

$1 \cdot$

1 -

9 -

17 -

20 -

JOTML 22 (score)

RINESTHETIC

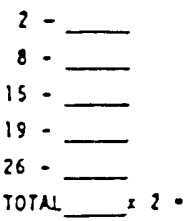
(score)

\section{INTILS}

II.

14.

16.

22 -

25 .

rote $\times 2$. (score)

\section{coses}

$$
\text { 3. }
$$

1.

5 .

21 -

0 .

ToTN 22 (sere)

\section{inoiriane}

is -

18 .

v.

28.

$\infty$

TOTN 22 (score)
Ms for Learning Style Preference Minor Learning Style Preference kegligiole 
APPENDIX D

GREEK TRANSLATIONS 


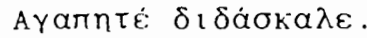

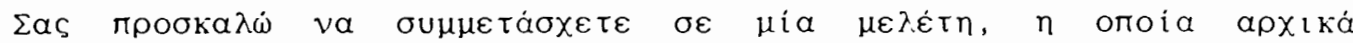

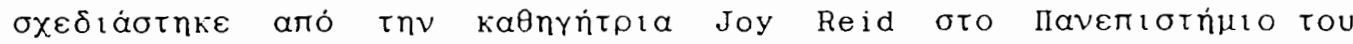

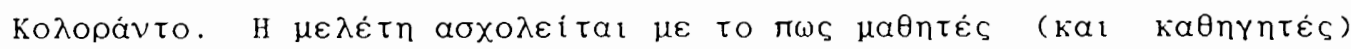

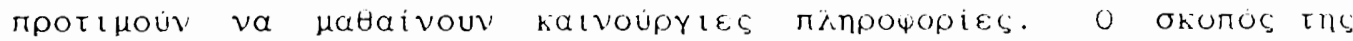

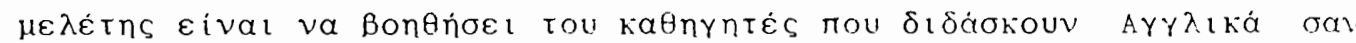

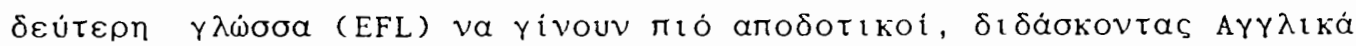

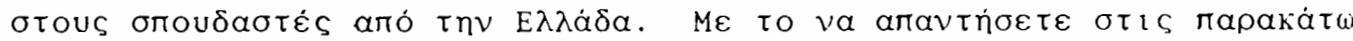

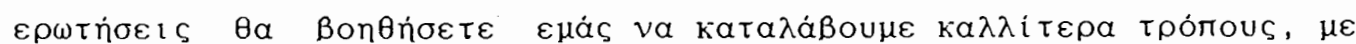

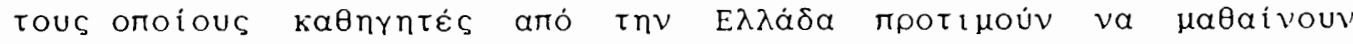

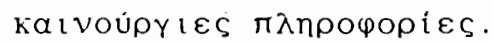

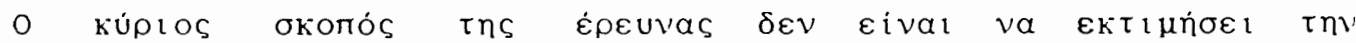

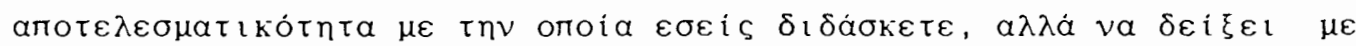

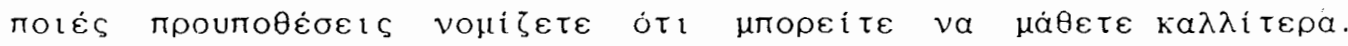

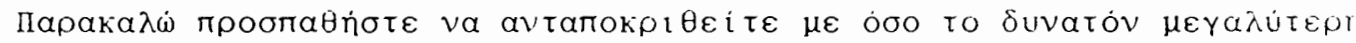

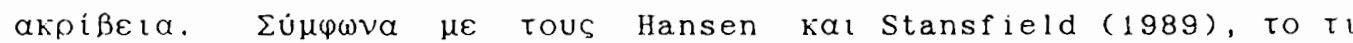

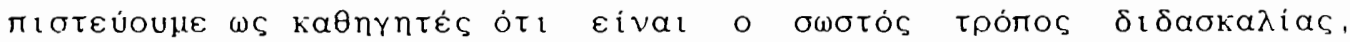

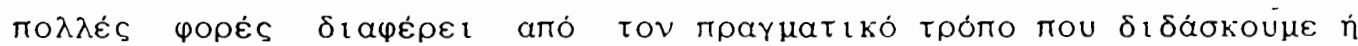
$\mu \alpha \theta \alpha i v o u \mu \varepsilon$.

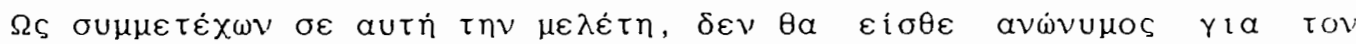

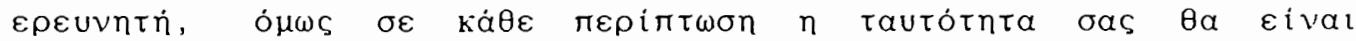

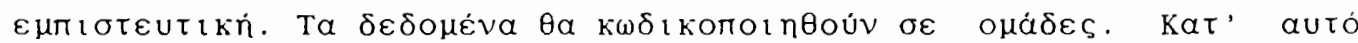

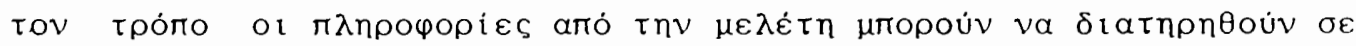

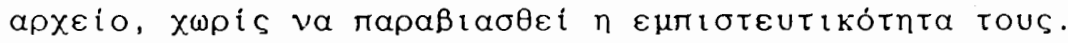

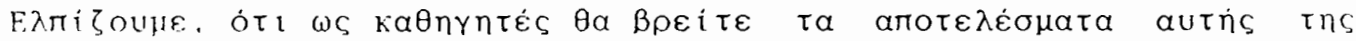

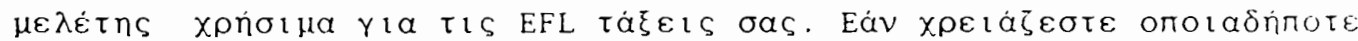

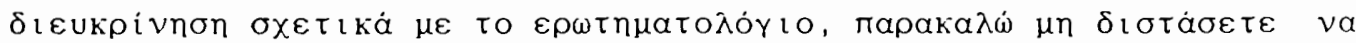

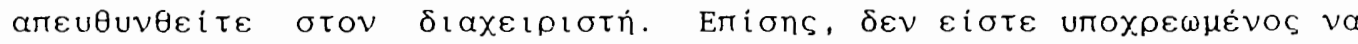

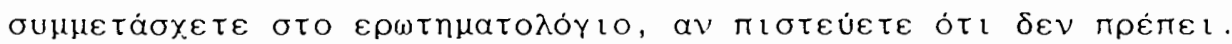




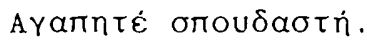

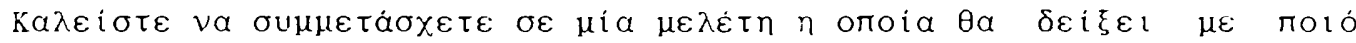

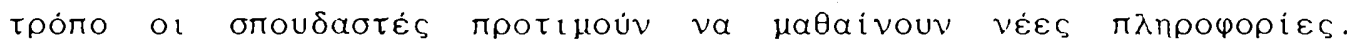

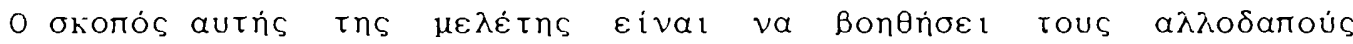

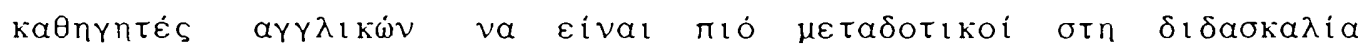

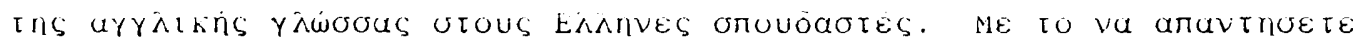

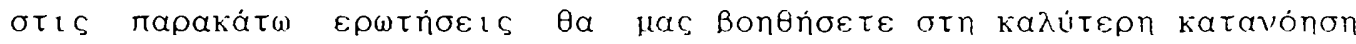

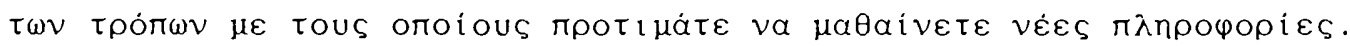

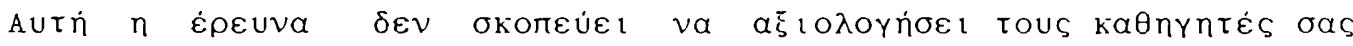

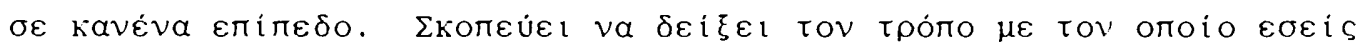

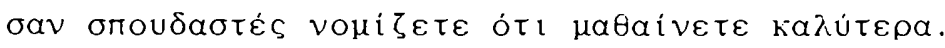

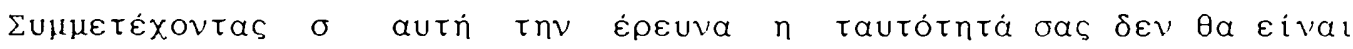

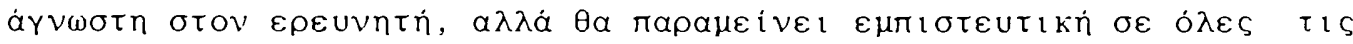

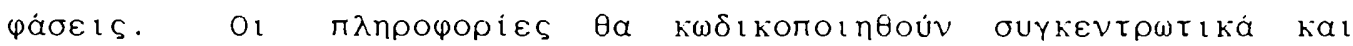

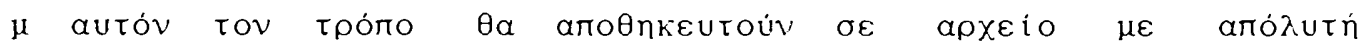

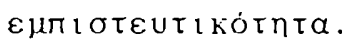

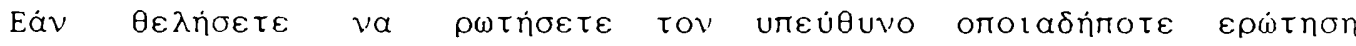

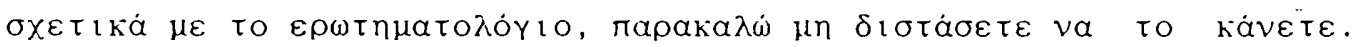

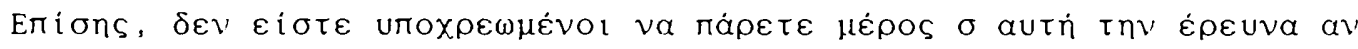

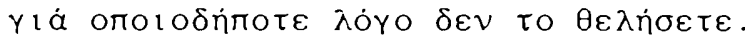


Ayañtoi roveis.

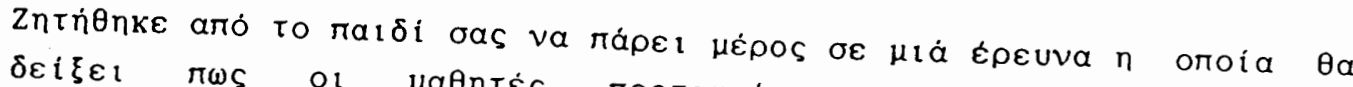

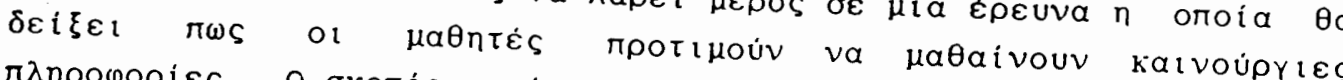

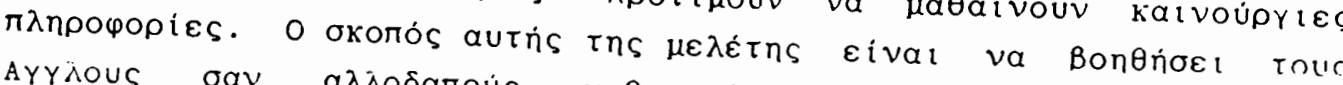

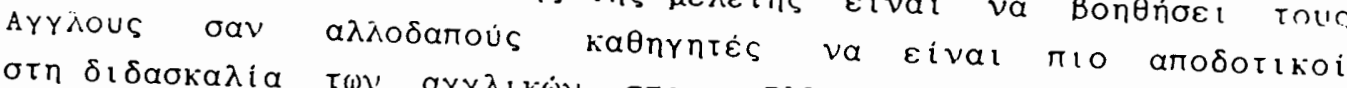

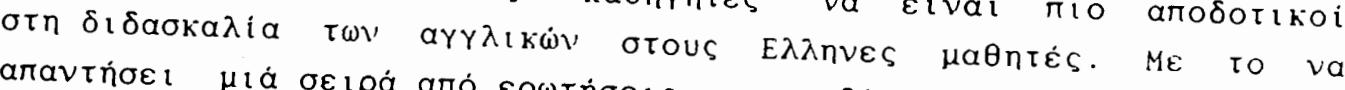

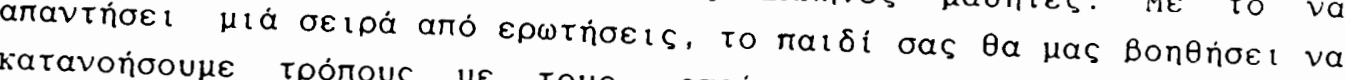

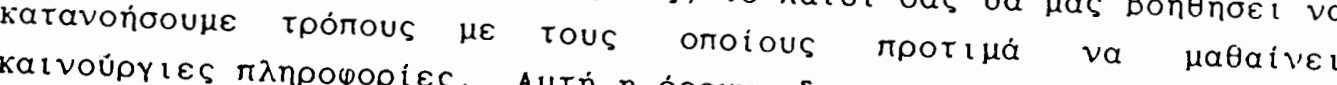

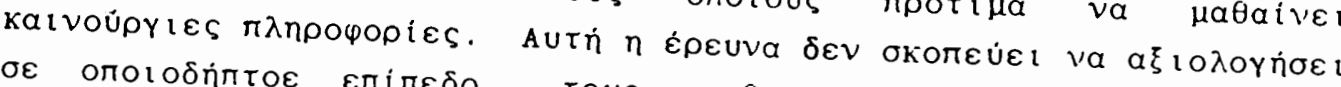

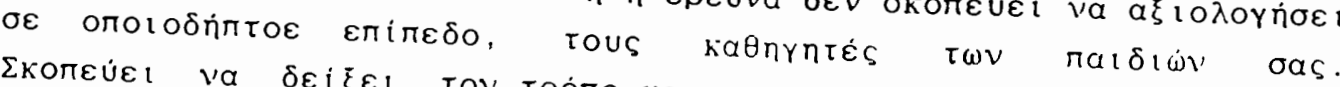

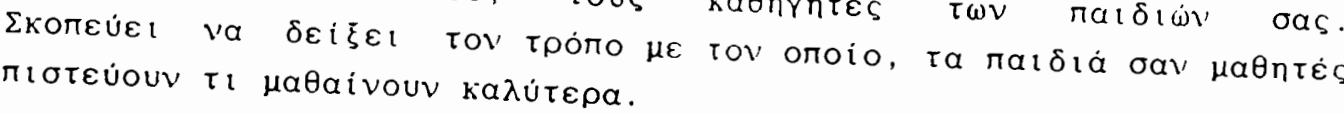

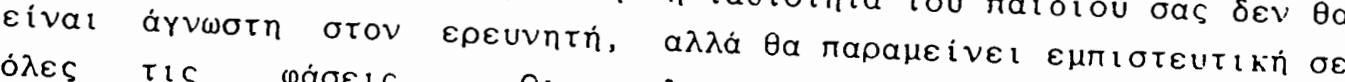

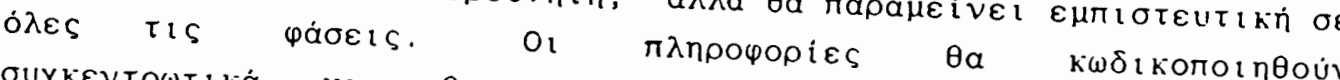

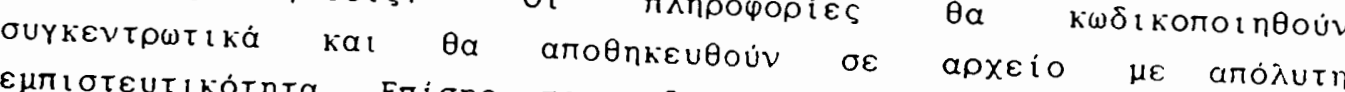

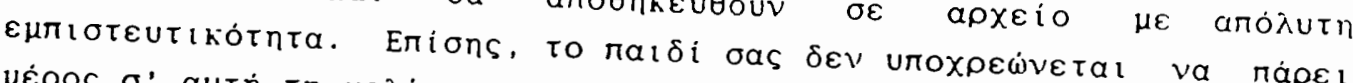

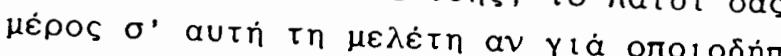


ШАНРОФОР IАKН ФОРМА

Eүं் $0 / \eta$

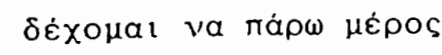

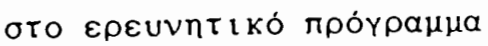

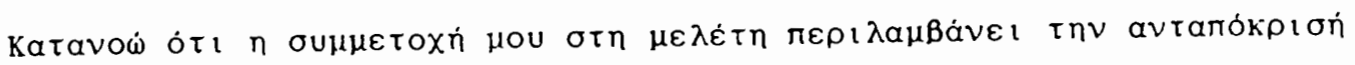

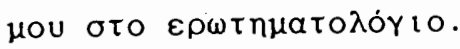

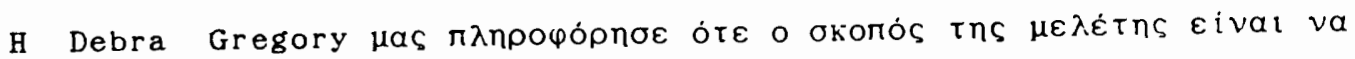

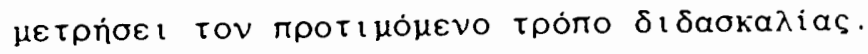

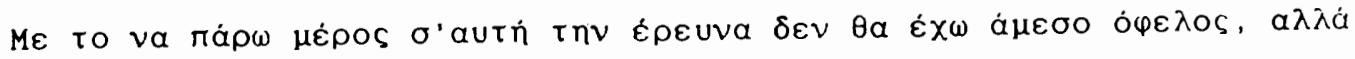

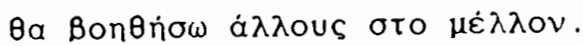

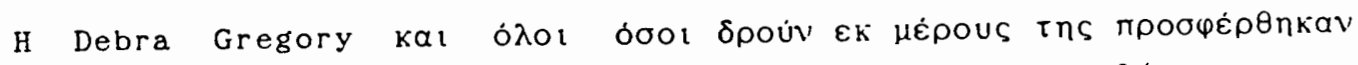

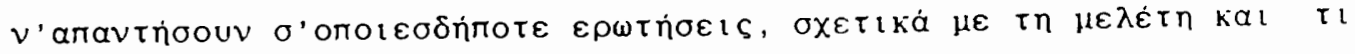

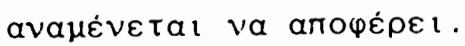

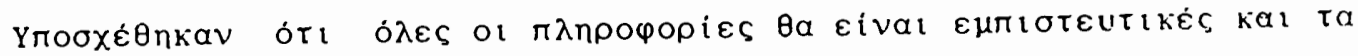

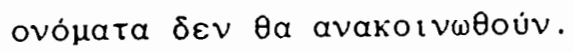

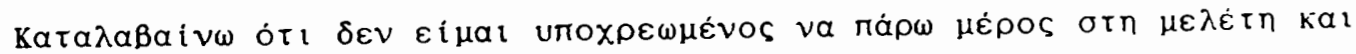
ót

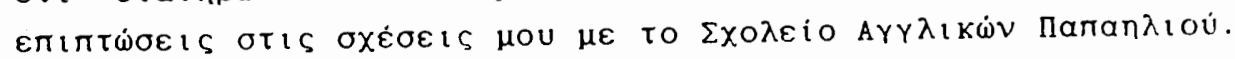

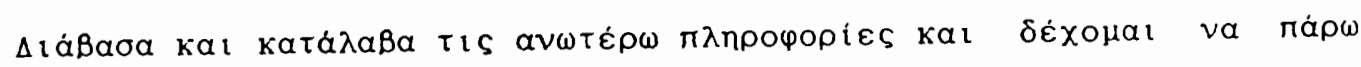

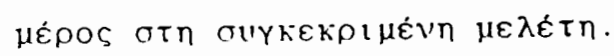

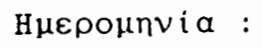

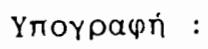




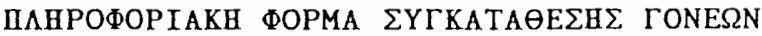

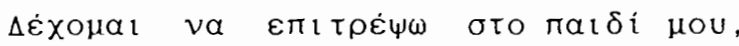

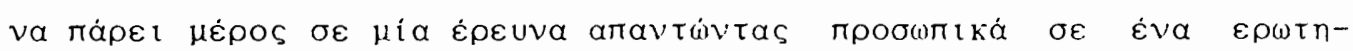

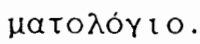

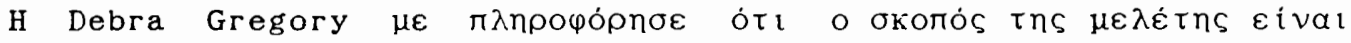

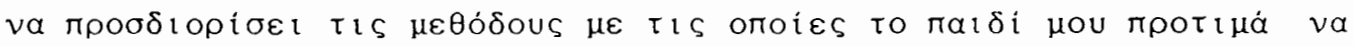

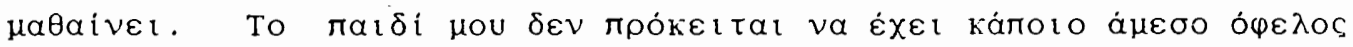

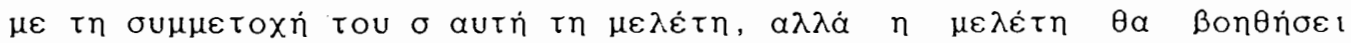

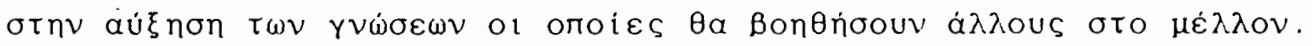

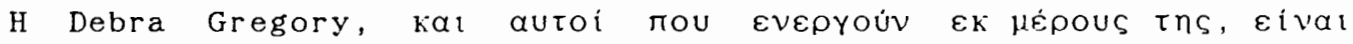

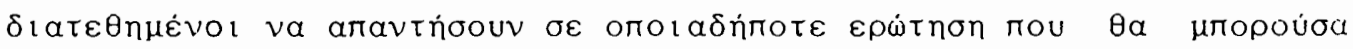

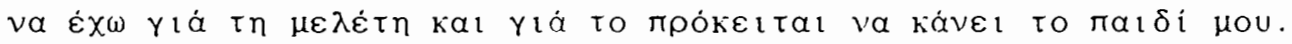

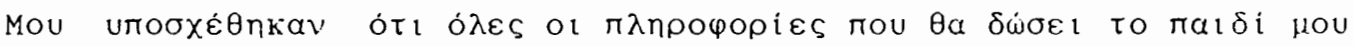

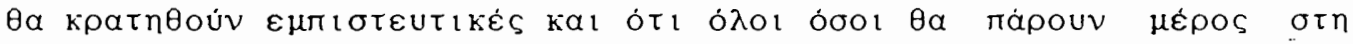

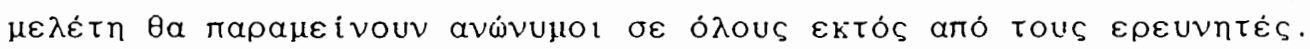

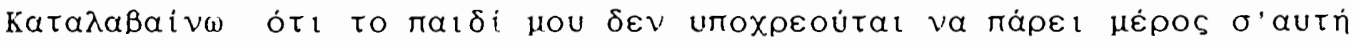

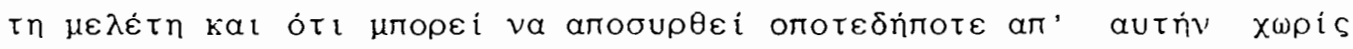

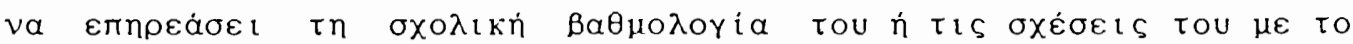

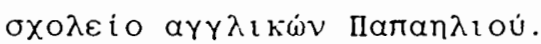

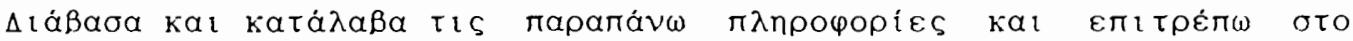

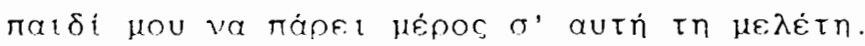

Huepounvia : Yлоүрафń : 


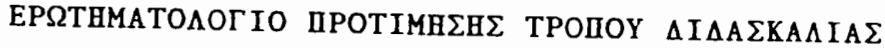

ONOM/NYMO $\mathrm{H} \Lambda \mathrm{IK} I \mathrm{~A}$ HMEPOMHN IA

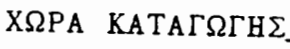
MHTPIKH $\Gamma \Lambda \Omega \Sigma \Sigma A$ AIOФOITOE $\Sigma \Pi O Y \triangle A \Sigma T H \Sigma$ AN $\triangle P A \Sigma$ TYNAIKA

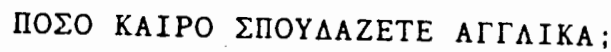
ПOIA EINAI H KYPIA EIDIKOTHTA $\Sigma A \Sigma$; 


\section{OAHIIES:}

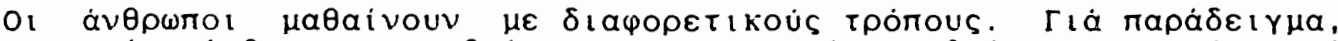

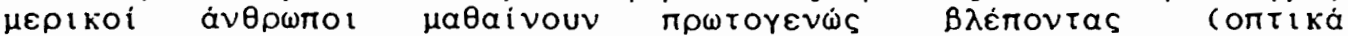

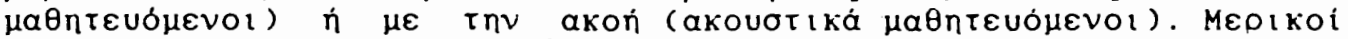

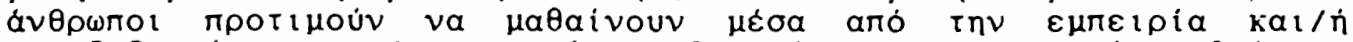

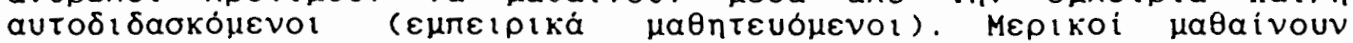

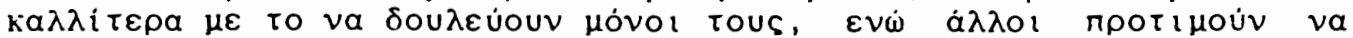

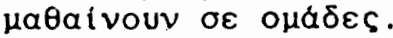

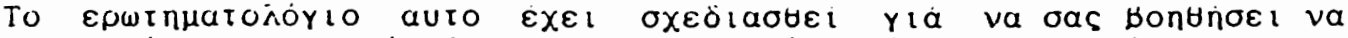

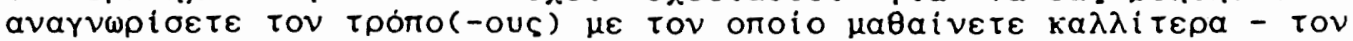

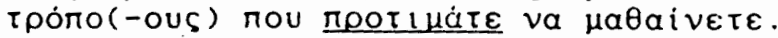

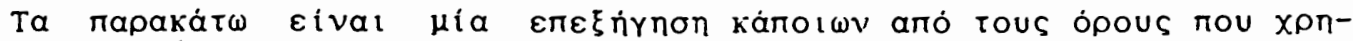

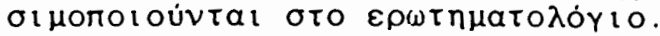

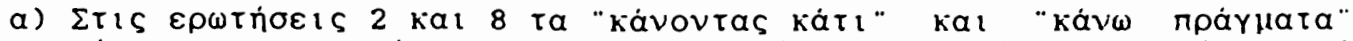

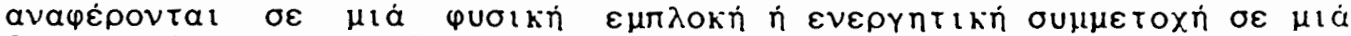

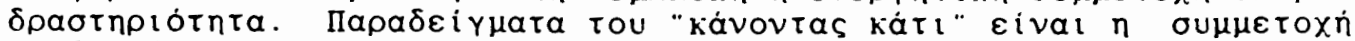

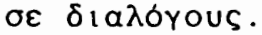

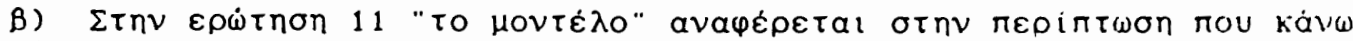

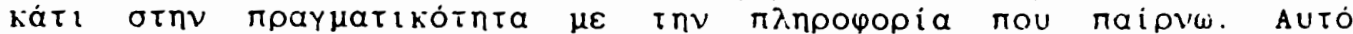

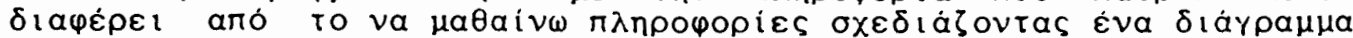

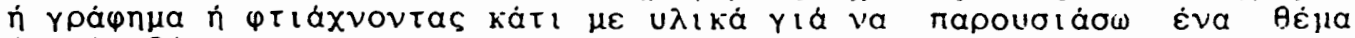
n் $\mu \imath \dot{\alpha} \imath \delta \dot{\varepsilon} \alpha$.

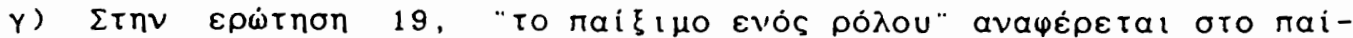

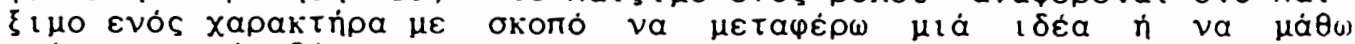

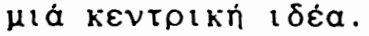

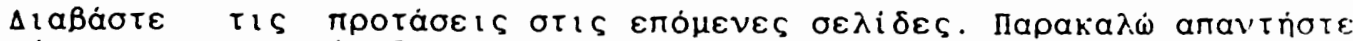

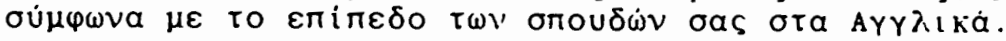

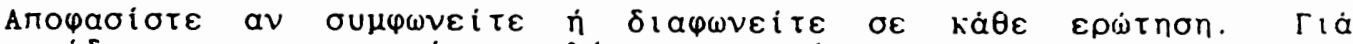

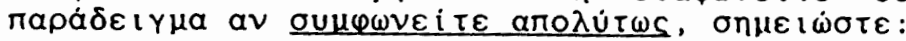

\begin{tabular}{|l|l|l|l|l|}
$\Sigma A$ & $\Sigma$ & $A$ & $\Delta$ & $\Delta A$ \\
\hline$x$ & & & & \\
\hline
\end{tabular}

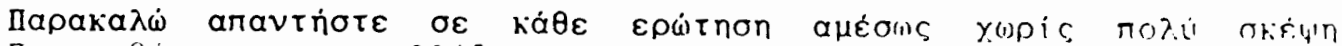

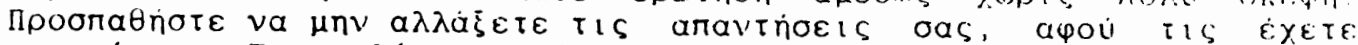

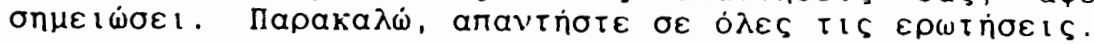


EPSTHMATOAOTIO MPOTIMHEH

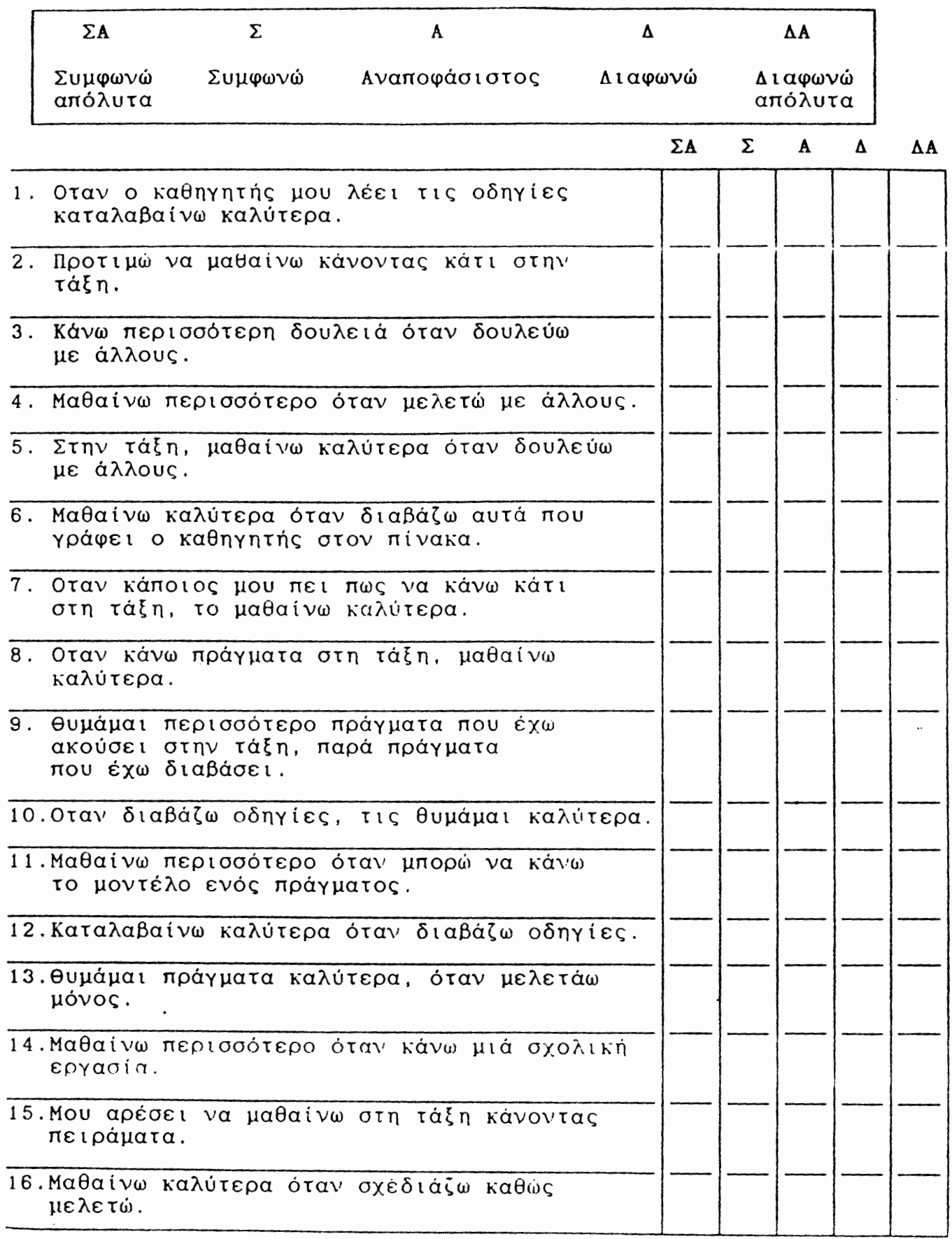


EPSTHMATOAOTIO DPOTIMHEH

\begin{tabular}{|c|c|c|c|c|}
\hline$\Sigma A$ & $\Sigma$ & A & $\Delta$ & $\Delta \mathbf{A}$ \\
\hline 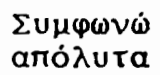 & $\Sigma \cup \mu \varphi \omega \nu \dot{\omega}$ & Avaropáolotos & $\Delta\llcorner$ เ $\omega \nu \dot{0}$ & $\begin{array}{l}\Delta 1 \alpha \varphi \omega v \dot{\omega} \\
\alpha \pi \dot{\lambda} u \tau \alpha\end{array}$ \\
\hline
\end{tabular}

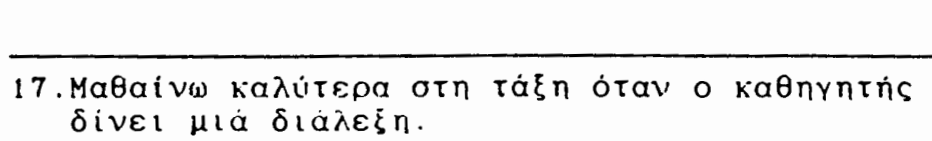

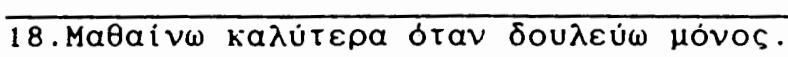

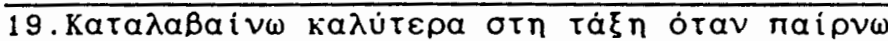

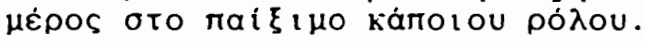

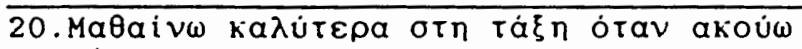
kámo ov.

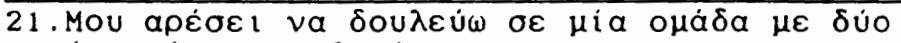

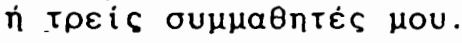

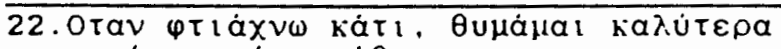

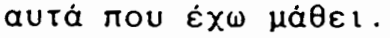

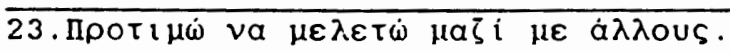

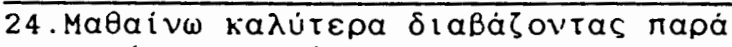
akoúyovtas károlov.

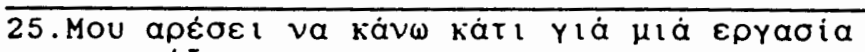
tns tákns.

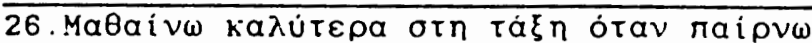

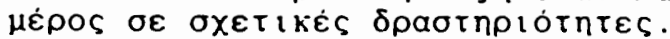

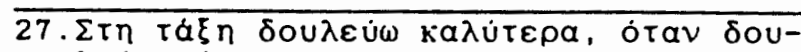
$\lambda \varepsilon \dot{u} \omega$ jóvos.

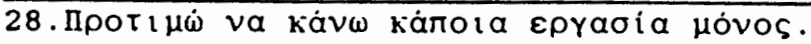

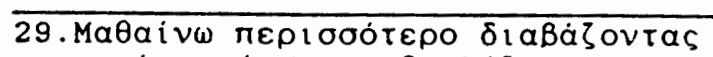

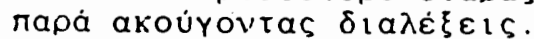

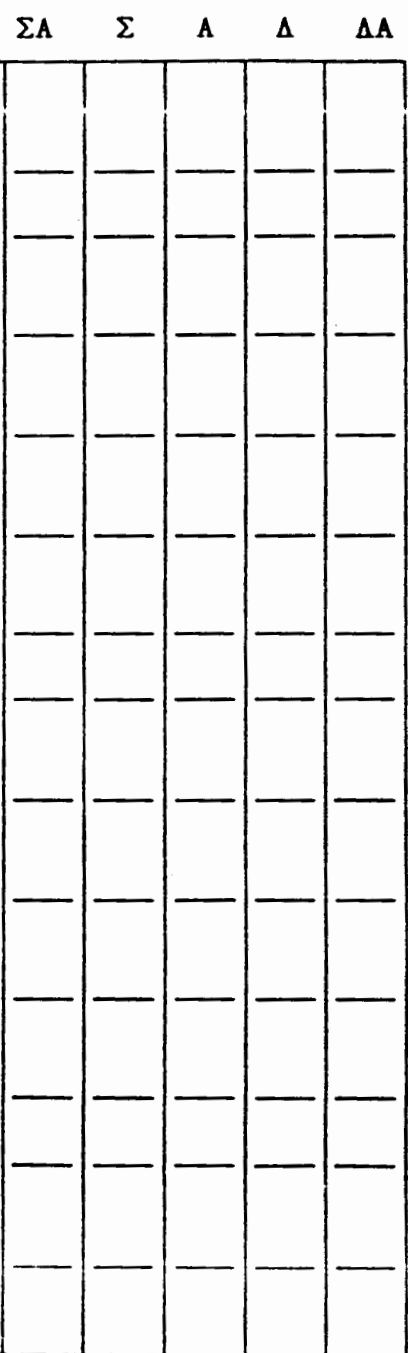


APPENDIX E

BACKTRANSLATIONS 
Dear stuciert,

We invite you to take part in a study that will show us the way students prefer to learn new information. The scope of this study is to help the foreign English teacher to be more effective in teaching English to Greek students. By answering the following questions it will help us to understand more the best way you learn rew information. The scope of this study is not to evaluate you as teachers at any level. Its scope is to show the way that you students think you learn better.

Taking part in this study, your identity will be known to the researcher but will be kept confidential at ail leveis of the study. All the information will be coded and will be placed in files with confidentiality.

If you want to ask any questions of the administrator of the questionnairre, feel free to do so. If for any reason you do not want to take part in this study you are not required to do so.

This study is being supervised by Professor Devorah Lieberman. If by participating in this study you experience any problems, please contact professor Lieberman, (503) 725-3534, or the secretary of the Human Subjects Research Review Committee, Office of Grants and Contracts, 105 Neuberger Hall, Portland state University. 
Dear instructor,

I invite you to take part in a study that was originally developed by the professor Joy Reid, of the university of colorado. The purpose of the study is to see how students (and teachers) prefer to learn new information. The scope of this study is to help the teachers that teach English as a foreign language (EFL) to become more productive in teaching English to students from Greece. By answering the following questions it will help us to better understand the ways that instructors from Greece prefer to learn new information. The main scope of this study is not to evaluate your abilities as a teacher but to show to us under what circumstances you think that you can learn better. Please try to answer the questions truthfully. According to Hansen and stansfield (1989), what we believe as teachers is the right way of teaching many times defers from how we actually teach or learn.

Your identity will be known to the researcher, but will be kept confidential. The answers will be coded. By doing this all information from the study will be kept in files with confidentiality.

We hope as instructors you will find the results of this study useful for the EFL classes. If you need any additional information for the questionnaire please feel free to ask the administrator of the exam. Also, you are not under obligation to take part in this questionnaire.

This study is being supervised by Frofessor Devorah Lieberman. If by participating in this study you experience any problem, please contact frofessor Lieberman (503) 725-3534, or the secretary of the Human Subjects Research Review Committee, office of Grants and Contracts, 105 Neuberger Hall, Portland State University. 
Dear Parent:

Your child is being asked to take part in a study that will show how students prefer to iearn new information. The scope of this siudy is to help the foreign Engi isi langliage instructor to be more productive in teaching English to Greek students. Ey answering the questions your child will help us to understand better the ways in which he prefers to learn new information. This study is not to evaluate your child's teacher but will show us the best way that your child believes he learns better.

Taking part in this study, your child's identity will be known to the researcher but will remain unknown to all others. Also your child is not obligated to take part in this study if he wishes not to for any reason.

This study is being supervised by Frofessor Devorah Lieberman. If by participating in this study you experience any problem, please contact professor Lieberman, (503) 725-3534, or the secretary of the Human Subjects Research Review Committee, Office of Gransts and Contracts, 105 Neuberger Hall, Fortland state university. 


\section{INPORMED CONSENT FORM}

I study accept taking part in this

I understand that my part in this study includes my answering questions to a questionnaire.

Debra Gregory informed us that the scope of this study is to show us our preferred way of learning.

By taking part in this study, it will not help me but it will help others in the future.

Debra Gregory and anyone associated with this study offer their assistance with any questions related to the study and the expectations following the results.

They promise that all information will be kept confidential and the names of the participants will remain anonymous.

I understand that I am not obligated to take part in this study and I reserve the right not to take part without it hurting my relationship with the papaeliou school.

I have read all the above information and I accept taking part in this study.

Date 


\section{INEORMED FARENTAL CONSENT EORM}

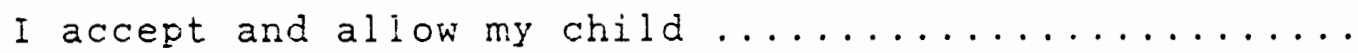
to take part in this study, answering personally to the questionnaire.

Debra Gregory has informed us that the scope of this study is to identify the ways that my child prefers to learn. My child will not benefit by taking part in this study, but the study will help increase the knowledge that will help others in the future.

Debra Gregory and those associated with her are in a position to answer any type of question triat I may wish to ask and anytring related to my child.

They promised me that any information reported by my child will be kept confidentia! and the information will be anonymous to all except the researcher.

I understand that my child is not obligated to take part in this study and at any moment he can withdraw without any conflicts with his grades or with his school.

I read the above information and I allow my child to take part in this study.

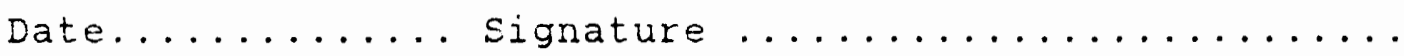


PERCEPTUAL LEARNING STYLE PREFERENCE QUESTIONNAIRE

Name/surname age date

country of origin native language

graduate undergraduate male female

How long have you studied English?

What's your occupation/area of interest?

Instructions:

Feople learn in many different ways. For example, some people learn by seeing (visual learning) or with hearing (auditory learning). Some people prefer to learn through experience (kinesthetic learning) or with using their hands (tactile learning). Some learn best by working by themselves, but others prefer to learn in groups. The questionnaire has been designed to helf you recognize the way or ways you learn best--the way (ways) you prefer to learn.

The following is an explanation of the names that will be used in the questionnaire.

a) in questions 2 and 8 , "doing something" and "doing things" refers to physical involvement or taking part in a project. Going on a class excursion or taking part in drama activities are examples.

b) in question 11 "the model" refers to making something in reality with the information talen, such as drawing diagrams or graphs.

c) In question 19 the "playing of a role" refers to the playing of a character with a scope of transferring an idea or learning one central idea.

d) Read the sections in the next pages. Flease answer the sections according to how you study English. Decide how true each section is for you, for example, if you believe it's absclutely true, if you agree somewhat, if it's neutral, if you disagree somewhat or if you believe it's absolutely untrue. 
Please answer the following questions without giving any thought. Try not to change your answers after you mark them.

PREFERRED LEARNING STYLE QUESTIONNAIRE

Absolutely Agree Undecided
$\begin{aligned} & \text { True } \\ & \text { Trisagree }\end{aligned}$

1. When the instructor tells me the information I learr better.

2. I prefer to learn by doing something in the classroom.

3. I do more work when i work with others.

4. I learn more when I study with others.

5. In the classroom I learn more when I work with others.

6. I learn more when the instructor puts the information on the board.

7. When someone tells me to do something in the classroom, I learn more.

8. When I do things in the classroom I learn more.

9. I remember things that I heard in the classroom, rather than things that i have read.

10. When I read instructions I remember more.

11. I learn more wher I can do a model.

13. I remember things more when I study by myself.

14. I learn more when I do a school project.

15. I prefer to learn in the classroom by doing experiments.

16. I learn more by drawing while I am studying.

17. I learn better in the classroom while the instructor is giving a lecture.

18. I learr more when I work by myself.

19. I understand better in the classroom when I play a role.

20. I learn better in the class when I listen to someone.

21. I like to work in a group with two or three students.

22. When I build something, I remember the things that I have learned more.

23. I prefer to study with others.

24. I iearn better by reading rather than by listening to someone.

25. I like to do something for a school project.

26. I learn better in the classroom when I take part in the action. 
27. In the class I work betler when I work by myseli.

28. I prefer to do a project by myself.

20. I learn more by reading books rather than by

listening to lectlires.

30. I prefer to work alone. 


\section{OFFICE OF GRANTS AND CONTRACTS}

\footnotetext{
DATE: January 4, 1992

TO: Debra Jane Gregory

RE: Martha Balshem, Chair, HSRRC 1992-93 Mutha Badshem/At HSRRC Approval of Your Application tilled "The Preferred Leaming..." covering the protoction of human subjects. The committee is DHHS policies and regulations for protecting the rights and weifare of all subjects participating isfied that your provisions and your project is approved. Any changes in the proposed study, or any unanticipated problems involving risk to subjects, should be reported to the Human Subjects Research Review Committee. An annual repont of
the status of the project is required.

c. Office of Graduate Studies
} 
APPENDIX G

Department of English

P.O. Box 3353

Laramie, Wyoming $82071 \cdot 3353$

April 16, 1994

(307) $766-6452$

\section{UWYOMING}

Debra Gregory

4105 Fir Street

Vancouver, WA 98660

\section{Dear Debra:}

Thanks for your recent phone call. I am delighted to give you permission to use my Perceptual Leaming Styles Preference survey in your graduate work. I look forward to seeing your results.

If you need additional assistance, please contact me. My various addresses are below.

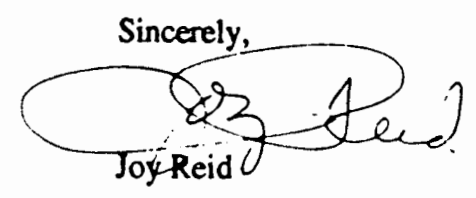

School Year

Weekdays

Summers \&

Weekends
Department of English

University of Wyoming

Laramie, WY $82071-3353$

1344 Fairview Drive

Fon Collins, CO 80521
(307) 766-2146

(phone, fax, answering machine)

e-mail: jreid@uwyo.edu

(303) 493-3902

(phone, fax, answering machine)

e-mail: sreid@lamar.colostate.edu 
APPENDIX H

\section{THE PAPAELIOU}

SCHOOLS OF FNGLLISH

lli korolskow SI - 18532 Plioeus 35 vonzeiou St. - is: 12 Purous

ind $4173892-f 0 x$ 4121520 ind \&1184PC - i0x \$121312

FAX TRANSMISSION

from Diano Popoetion

10

\begin{tabular}{|c|c|}
\hline $\begin{array}{l}\text { Company } \\
\text { fox to } \\
\text { Popes }\end{array}$ & 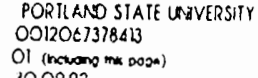 \\
\hline
\end{tabular}

Poges Ol (nowano now popa)

Dear Sirs.

We are a well established Language Scinool in Piacus, Greece. Ms Deboran Cregory has asked for nermisslon, to do a survey at our Profletenc; class studenis' learning preferences. She also wants iniormation in our teachers' educutional hackground

We have no objection to the above survey and w'e assure vou that $M_{5}$ regory has our full approval.

The number of students involved in the suivey ore Proficiency leve sludents. Half of them are teenggers [13-17] and half of them adults [18 and abovel

We remain at your disposal for sny further information.

Diana Papaeliou

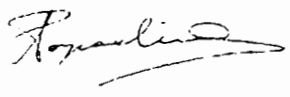

Litector of Studies 
APPENDIX I

RAW DATA 
$\begin{array}{lllllllll}\text { AGE } & M / F & Y & V & A & K & T & G & \text { I }\end{array}$ $\begin{array}{llllllll}29 & F & 40 & 24 & 36 & 32 & 32 & 24\end{array}$

$\begin{array}{llllllll}31 & F & 38 & 38 & 44 & 38 & 30 & 38\end{array}$

$\begin{array}{lllllllll}52 & F & 10 & 38 & 38 & 46 & 40 & 34 & 28\end{array}$

$\begin{array}{lllllllll}37 & M & 20 & 44 & 36 & 42 & 46 & 46 & 48\end{array}$

$\begin{array}{llllllll}39 & M & 24 & 40 & 42 & 34 & 40 & 20\end{array}$

$\begin{array}{lllllll}F & 38 & 32 & 44 & 40 & 38 & 20\end{array}$

$\begin{array}{lllllllll}42 & F & 15 & 32 & 44 & 50 & 50 & 28 & 44\end{array}$

$\begin{array}{lllllllll}22 & F & 12 & 28 & 34 & 40 & 44 & 22 & 50\end{array}$

$\begin{array}{lllllllll}27 & M & 13 & 48 & 36 & 50 & 34 & 34 & 44\end{array}$

$\begin{array}{lllllllll}31 & F & 17 & 44 & 38 & 38 & 50 & 24 & 50\end{array}$

$\begin{array}{llllllll}27 & F & 44 & 38 & 36 & 46 & 30 & 42\end{array}$

$\begin{array}{lllllllll}16 & F & 8 & 38 & 28 & 42 & 36 & 20 & 38\end{array}$

$\begin{array}{lllllllll}16 & M & 8 & 36 & 40 & 44 & 40 & 26 & 50\end{array}$

$\begin{array}{lllllllll}15 & \mathrm{~F} & 7 & 38 & 38 & 34 & 26 & 22 & 50\end{array}$

$\begin{array}{lllllllll}17 & M & 10 & 32 & 38 & 46 & 40 & 30 & 32\end{array}$

$\begin{array}{lllllllll}15 & M & 5 & 32 & 40 & 50 & 40 & 50 & 20\end{array}$

$\begin{array}{lllllllll}15 & M & 8 & 26 & 38 & 36 & 34 & 36 & 18\end{array}$

$\begin{array}{lllllllll}16 & M & 8 & 34 & 34 & 44 & 38 & 30 & 36\end{array}$

$\begin{array}{lllllllll}16 & M & 8 & 48 & 22 & 46 & 40 & 28 & 24\end{array}$

$\begin{array}{lllllllll}16 & M & 10 & 32 & 28 & 22 & 24 & 28 & 32\end{array}$

$\begin{array}{lllllllll}15 & M & 9 & 22 & 34 & 38 & 40 & 28 & 34\end{array}$

$\begin{array}{lllllllll}16 & M & 8 & 38 & 36 & 40 & 44 & 24 & 50\end{array}$

$\begin{array}{lllllllll}16 & F & 8 & 40 & 38 & 46 & 42 & 32 & 20\end{array}$

$\begin{array}{lllllllll}16 & M & 10 & 34 & 32 & 24 & 24 & 26 & 38\end{array}$

$\begin{array}{lllllllll}15 & F & 6 & 28 & 36 & 40 & 36 & 32 & 36\end{array}$

$\begin{array}{lllllllll}15 & F & 8 & 46 & 32 & 48 & 48 & 14 & 42\end{array}$

$\begin{array}{lllllllll}15 & F & 8 & 24 & 38 & 34 & 28 & 34 & 26\end{array}$

$\begin{array}{lllllllll}15 & F & 9 & 42 & 20 & 30 & 24 & 22 & 28\end{array}$

$\begin{array}{lllllllll}16 & F & 9 & 42 & 20 & 30 & 24 & 22 & 30\end{array}$

$\begin{array}{lllllllll}17 & M & 8 & 28 & 28 & 38 & 38 & 44 & 14\end{array}$

$\begin{array}{lllllllll}15 & F & 7 & 40 & 34 & 46 & 48 & 32 & 20\end{array}$

$\begin{array}{lllllllll}16 & F & 8 & 24 & 28 & 38 & 36 & 26 & 26\end{array}$

$\begin{array}{lllllllll}15 & M & 6 & 30 & 34 & 44 & 38 & 44 & 16\end{array}$

$\begin{array}{lllllllll}14 & M & 9 & 32 & 40 & 50 & 40 & 50 & 20\end{array}$

$\begin{array}{lllllllll}17 & M & 8 & 24 & 38 & 44 & 42 & 36 & 26\end{array}$ 
$\begin{array}{lllllllll}15 & \mathrm{~F} & 7 & 36 & 26 & 44 & 36 & 34 & 28\end{array}$

$\begin{array}{lllllllll}17 & F & 10 & 32 & 36 & 34 & 32 & 30 & 40\end{array}$

$\begin{array}{lllllllll}16 & F & 9 & 36 & 40 & 38 & 28 & 36 & 28\end{array}$

$\begin{array}{lllllllll}16 & \mathrm{~F} & 7 & 34 & 32 & 32 & 36 & 32 & 40\end{array}$

$\begin{array}{lllllllll}16 & M & 10 & 22 & 46 & 28 & 36 & 26 & 28\end{array}$

$\begin{array}{lllllllll}16 & M & 9 & 34 & 32 & 42 & 40 & 32 & 32\end{array}$

$\begin{array}{lllllllll}16 & F & 9 & 38 & 34 & 40 & 44 & 36 & 32\end{array}$

$\begin{array}{lllllllll}16 & M & 9 & 40 & 38 & 38 & 32 & 32 & 38\end{array}$

$\begin{array}{lllllllll}16 & F & 8 & 26 & 28 & 36 & 40 & 34 & 30\end{array}$

$\begin{array}{lllllllll}20 & F & 9 & 30 & 30 & 48 & 44 & 24 & 32\end{array}$

$\begin{array}{lllllllll}20 & F & 9 & 32 & 36 & 50 & 24 & 16 & 38\end{array}$

$\begin{array}{lllllllll}19 & M & 8 & 42 & 32 & 38 & 46 & 26 & 36\end{array}$

$\begin{array}{lllllllll}21 & M & 9 & 50 & 36 & 16 & 32 & 26 & 50\end{array}$

$\begin{array}{lllllllll}21 & F & 7 & 38 & 34 & 26 & 32 & 26 & 40\end{array}$

$\begin{array}{lllllllll}19 & F & 9 & 36 & 38 & 32 & 38 & 38 & 42\end{array}$

$\begin{array}{lllllllll}19 & F & 9 & 38 & 34 & 36 & 20 & 16 & 38\end{array}$

$\begin{array}{lllllllll}18 & M & 8 & 44 & 40 & 30 & 42 & 18 & 50\end{array}$

$\begin{array}{lllllllll}19 & F & 9 & 38 & 36 & 36 & 30 & 24 & 40\end{array}$

$\begin{array}{lllllllll}20 & F & 11 & 46 & 38 & 36 & 38 & 18 & 42\end{array}$

$\begin{array}{lllllllll}24 & F & 8 & 38 & 30 & 38 & 34 & 32 & 32\end{array}$

$\begin{array}{lllllllll}23 & F & 6 & 30 & 40 & 42 & 38 & 32 & 22\end{array}$

$\begin{array}{lllllllll}19 & M & 10 & 42 & 34 & 40 & 34 & 38 & 28\end{array}$

$\begin{array}{lllllllll}20 & F & 8 & 32 & 42 & 28 & 38 & 20 & 44\end{array}$

$\begin{array}{lllllllll}19 & M & 2 & 42 & 24 & 36 & 38 & 24 & 44\end{array}$

$\begin{array}{lllllllll}18 & F & 10 & 38 & 36 & 32 & 24 & 32 & 28\end{array}$

$\begin{array}{lllllllll}24 & F & 8 & 40 & 40 & 36 & 38 & 32 & 38\end{array}$

$\begin{array}{lllllllll}19 & F & 9 & 42 & 36 & 44 & 40 & 28 & 42\end{array}$

$\begin{array}{lllllllll}19 & F & 7 & 34 & 32 & 42 & 38 & 28 & 32\end{array}$

$\begin{array}{lllllllll}19 & F & 6 & 42 & 32 & 40 & 32 & 26 & 40\end{array}$

$\begin{array}{lllllllll}22 & F & 8 & 38 & 34 & 34 & 32 & 22 & 44\end{array}$

$\begin{array}{lllllllll}20 & F & 9 & 32 & 40 & 24 & 24 & 26 & 42\end{array}$

$\begin{array}{lllllllll}20 & F & 8 & 36 & 36 & 30 & 32 & 20 & 38\end{array}$

$\begin{array}{lllllllll}23 & F & 12 & 30 & 34 & 38 & 44 & 46 & 20\end{array}$

$\begin{array}{lllllllll}18 & F & 8 & 40 & 40 & 42 & 34 & 24 & 32\end{array}$

$18 \quad F \quad \begin{array}{lllllll}10 & 32 & 36 & 42 & 36 & 34 & 26\end{array}$ 
$\begin{array}{lllllllll}19 & F & 8 & 34 & 40 & 34 & 46 & 34 & 26\end{array}$

$\begin{array}{lllllllll}18 & F & 9 & 40 & 26 & 32 & 38 & 32 & 40\end{array}$

$\begin{array}{lllllllll}19 & F & 9 & 46 & 42 & 44 & 42 & 44 & 28\end{array}$

$\begin{array}{lllllllll}19 & F & 9 & 32 & 38 & 32 & 32 & 42 & 20\end{array}$

$\begin{array}{lllllllll}19 & F & 6 & 30 & 36 & 36 & 38 & 40 & 18\end{array}$

$\begin{array}{lllllllll}20 & F & 10 & 36 & 38 & 30 & 32 & 38 & 26\end{array}$

$\begin{array}{lllllllll}20 & F & 4 & 34 & 40 & 46 & 42 & 28 & 32\end{array}$

$\begin{array}{lllllllll}19 & M & 9 & 40 & 30 & 44 & 42 & 32 & 40\end{array}$

$\begin{array}{lllllllll}28 & F & 5 & 42 & 44 & 44 & 46 & 30 & 32\end{array}$

$\begin{array}{lllllllll}20 & M & 6 & 20 & 28 & 42 & 26 & 14 & 50\end{array}$

$\begin{array}{lllllllll}21 & M & 8 & 40 & 28 & 22 & 26 & 40 & 34\end{array}$

$\begin{array}{lllllllll}27 & M & 9 & 38 & 40 & 40 & 32 & 32 & 30\end{array}$

$\begin{array}{lllllllll}20 & F & 10 & 46 & 28 & 30 & 42 & 28 & 44\end{array}$

$\begin{array}{lllllllll}19 & M & 7 & 40 & 38 & 40 & 24 & 32 & 40\end{array}$

$\begin{array}{lllllllll}20 & F & 9 & 38 & 36 & 30 & 26 & 30 & 44\end{array}$

$\begin{array}{lllllllll}19 & F & 9 & 44 & 28 & 32 & 30 & 40 & 18\end{array}$

$\begin{array}{lllllllll}23 & F & 10 & 30 & 32 & 36 & 36 & 38 & 30\end{array}$

$\begin{array}{lllllllll}20 & F & 9 & 38 & 30 & 38 & 40 & 26 & 38\end{array}$

$\begin{array}{lllllllll}25 & F & 9 & 46 & 42 & 44 & 42 & 32 & 26\end{array}$

$\begin{array}{lllllllll}19 & F & 9 & 30 & 32 & 30 & 26 & 28 & 32\end{array}$

$\begin{array}{lllllllll}18 & F & 8 & 30 & 34 & 48 & 36 & 48 & 24\end{array}$

$\begin{array}{lllllllll}18 & F & 8 & 32 & 42 & 36 & 40 & 22 & 48\end{array}$

$\begin{array}{lllllllll}23 & F & 10 & 36 & 32 & 34 & 30 & 48 & 20\end{array}$

$\begin{array}{lllllllll}19 & F & 7 & 30 & 42 & 40 & 34 & 38 & 28\end{array}$

$\begin{array}{lllllllll}19 & M & 8 & 32 & 32 & 40 & 34 & 28 & 32\end{array}$

$\begin{array}{lllllllll}20 & F & 8 & 36 & 36 & 44 & 36 & 16 & 50\end{array}$

$\begin{array}{lllllllll}18 & M & 12 & 36 & 38 & 42 & 34 & 40 & 36\end{array}$

$\begin{array}{lllllllll}19 & M & 6 & 30 & 46 & 38 & 20 & 12 & 46\end{array}$

$\begin{array}{lllllllll}23 & M & 6 & 30 & 36 & 34 & 20 & 18 & 20\end{array}$

$\begin{array}{lllllllll}25 & F & 4 & 44 & 38 & 42 & 22 & 34 & 30\end{array}$

$\begin{array}{lllllllll}21 & M & 9 & 48 & 44 & 24 & 20 & 36 & 20\end{array}$

$\begin{array}{lllllllll}22 & M & 7 & 46 & 42 & 40 & 42 & 36 & 24\end{array}$

$\begin{array}{lllllllll}25 & F & 9 & 36 & 40 & 50 & 28 & 38 & 48\end{array}$ 